Portland State University

PDXScholar

$5-1-1987$

\title{
Discontinuities in Normal 30 to 36 Month Old and 54 to 60 Month Old Female Children
}

Shelley Louise Arnold-Cockburn

Portland State University

Follow this and additional works at: https://pdxscholar.library.pdx.edu/open_access_etds

Part of the Speech Pathology and Audiology Commons Let us know how access to this document benefits you.

\section{Recommended Citation}

Arnold-Cockburn, Shelley Louise, "Discontinuities in Normal 30 to 36 Month Old and 54 to 60 Month Old Female Children" (1987). Dissertations and Theses. Paper 3659.

https://doi.org/10.15760/etd.5541

This Thesis is brought to you for free and open access. It has been accepted for inclusion in Dissertations and Theses by an authorized administrator of PDXScholar. Please contact us if we can make this document more accessible: pdxscholar@pdx.edu. 
AN ABSTRACT OF THE THESIS OF She1ley Louise Arnold-Cockburn for the Master of Science in Speech Communication with an emphasis in Speech Pathology presented May 1, 1987.

Title: Discontinuities in Normal 30 to 36 Month and 54 to 60 Month old Female Children

APPROVED BY MEMBERS OF THE THESIS COMMITTEE:

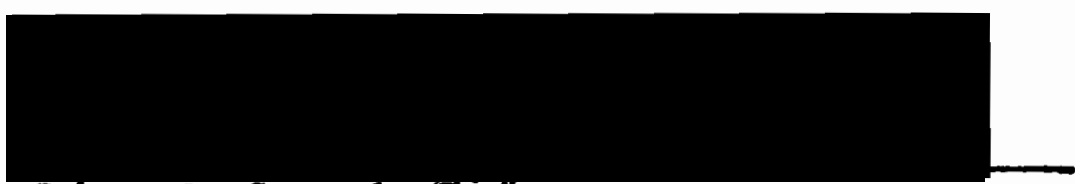

Robert L. Casteel, Chairperson

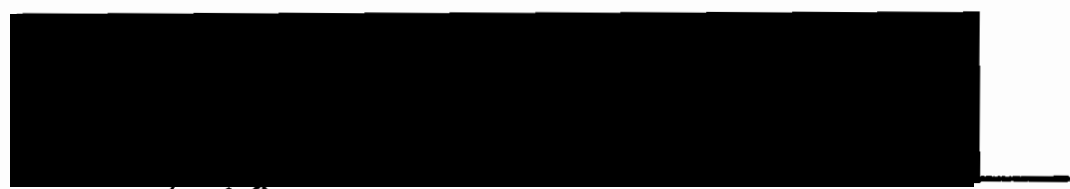
Mary T/ Wizhers

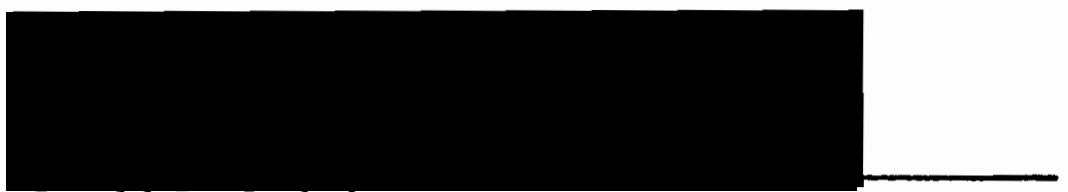

Gerald D. Guthrie

The purpose of this study was to compare the frequency of occurrence of specific discontinuities in 30 to 36 month old normal female children to normal 54 to 60 month old female children. Specifically, the discontinuities were categorized as follows: part word repetitions, whole word repetitions, and false starts. The discontinuities were observed while the child spontaneously interacted with an investigator in a clinical room. 
The following questions were addressed:

1) Do 30 to 36 month old normal female children differ in their total frequency of specific discontinuities when compared to normal 54 to 60 month old female children?

2) Do 30 to 36 month old normal female children demonstrate more part word repetitions than normal 54 to 60 month old female children?

3) Do 30 to 36 month old normal female children demonstrate more whole word repetitions than 54 to 60 month old normal female children?

4) Do 30 to 36 month old normal female children demonstrate more false starts than normal 54 to 60 month old female children?

Twenty normal female subjects from the greater Portland area were randomly selected from all children fitting selection criteria, to serve as subjects for this investigation. The group was divided into ten children from the 30 to 36 month old age group $(\bar{x}=33.7)$ and ten children from the 54 to 60 month old age group $(\vec{x}=57.7)$. Spontaneous speech samples were obtained for each subject. The subject's speech samples were transcribed verbatim from the recordings by the investigator, who then identified and classified specific discontinuities. A one way analysis of variance for independent means was performed to evaluate the degree of difference between all types of discontinuities in the two age groups. The results indicated a statistically significant difference exists between the two groups at the 0.05 level of probability for part word repetitions. Normal female children from the 30 to 36 month old age group demonstrated a significantly higher number of part word repetitions than the 54 to 60 month old age group. No other statistically significant differences were found.

In examining the data resulting from the study, it was concluded: 
1) Normal female children from the 30 to 36 month o1d age group used significantly more part word repetitions than the 54 to 60 month old age group.

2) There was no statistically significant difference in the total targeted discontinuities between the two age groups of normal female children.

3) There was no statistically significant difference in the number of whole word repetitions used by the two age groups of normal female children.

4) There was no statistically significant difference in the number of false starts used by the two age groups of normal female children. The results of this study point to part word repetitions as a good indicator of speech immaturity in young preschool children. 
DISCONTINUITIES IN NORMAL 30 TO 36 MONTH OLD AND

54 TO 60 MONTH OLD FEMALE CHILDREN

by

SHELLEY LOUISE ARNOLD-COCKBURN

A thesis submitted in partial fulfillment of the requirements for the degree of

MASTER OF SCIENCE IN SPEECH COMMUNICATION:

with an emphasis in

SPEECH PATHOLOGY

PORTLAND STATE UNIVERSITY

1987 
TO THE OFFICE OF GRADUATE STUDIES AND RESEARCH:

The members of the Committee approve the thesis of Shelley Louise Arnold-Cockburn presented May 1, 1987.

Robert L. Castee1, Chairperson

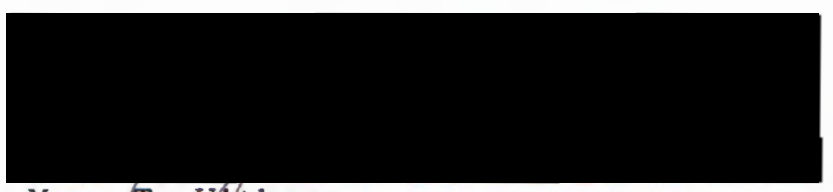

Mary'T. Wythers

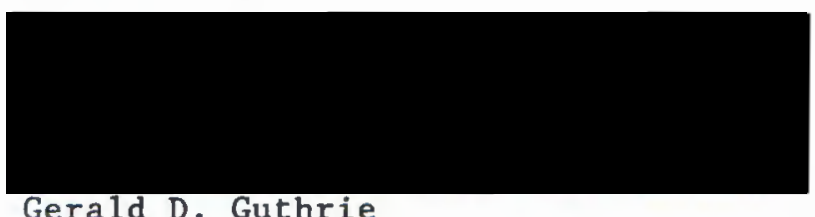

APPROVED :

Mary E. Gordon, Head, Department of Speech Communication

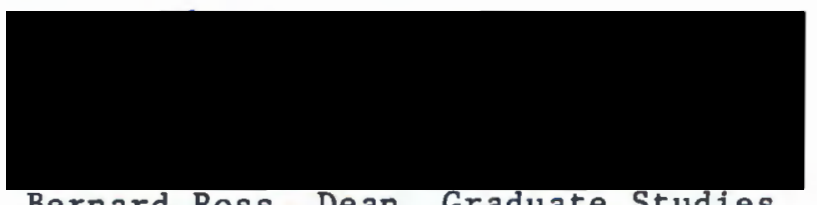

Bernard Ross, Dean, Graduate Studies and Research 


\section{ACKNOWLEDGEMENTS}

A very special thanks to Dr. Robert L. Casteel, whose unending guidance, patience, expertise, and clear thinking helped me complete my thesis. His continuous trust, faith, and support also encouraged and guided me in many other successful endeavors undertaken in graduate school. His help was above and beyond that of an advisor.

I also wish to thank Mary $T$. Withers whose enthusiasm, motivation, and re-write skills were invaluable in helping to complete this goal.

Most of a11, I wish to thank my mother, Ginger Arnold. Her infinite encouragement, 1ove, sacrifices and electronic office lab at Forest Grove High School, helped me not only complete this project but also undertake and accomplish many other projects throughout my 1 ife, that would not have been possible without her unending support. 
TABLE OF CONTENTS

PAGE

ACKNOWLEDGEMENTS

LIST OF TABLES

\section{CHAPTER}

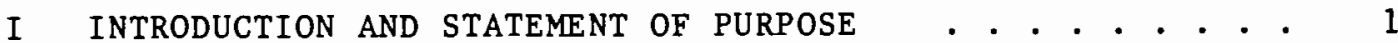

Introduction . . . . . . . . . . . . . . . . . . . . 1

Statement of Purpose . . . . . . . . . . . . 2

Definition of Terms ............... 3

II REVIEW OF THE LITERATURE . . . . . . . . . . . . 6

Normal Discontinuities in Preschool Children . . . . 6

Historical Perspective

Problems Observed in Earlier Studies

Recent Investigations Concerning Normal

Discontinuities

Summary ..................... 22

II METHODS . . . . . . . . . . . . . . . . 25

Subjects . . . . . . . . . . . . . . . . . 25

Instrumentation .. . . . . . . . . . . . . 26

Procedures ..................... . . . 27

Scoring Data and Analysis . . . . . . . . . . 28

Reliability ................ 29

IV RESULTS AND DISCUSSION . . . . . . . . . . . . . 32

Results ................... 32 


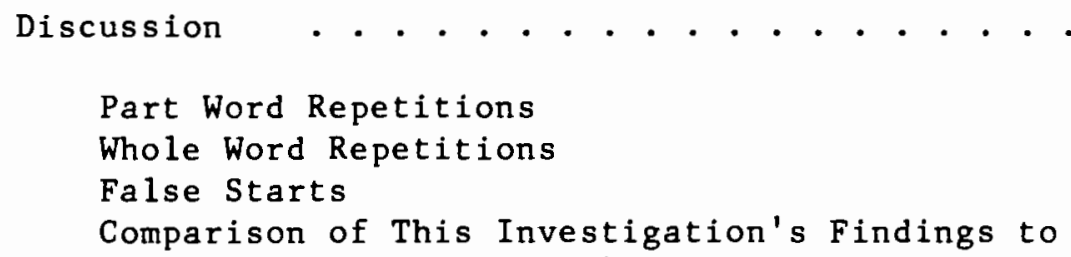

Part Word Repetitions

Whole Word Repetitions

False Starts

Comparison of This Investigation's Findings to Starkweather's (1985) Hypothesis

Various Factors Which May Affect Results . . . . . . . .

Procedures

Transcriptions

Setting

Client Interaction

Sumary . . . . . . . . . . . . . . . . . . . 53

V SUMMARY AND IMPLICATIONS . . . . . . . . . . . . . . . 55

Summary . . . . . . . . . . . . . . . . . 55

Implications . . . . . . . . . . . . . . . 57

Clinical

Research 


\section{LIST OF TABLES}

I Data Summary of Past Investigations on Normal

Discontinuities . . . . . . . . . . . . . . 8

II Summary of Means and Standard Deviations for Three

Individual Types of Discontinuities per 100

Words Spoken for 30 to 36 Month 01d and

54 to 60 Month 01d Female Children $\quad$. . . . . . . . . 33

II Summary of One Way Analysis of Variance for the Effect

of Age (30 to 36 Month 0ld vs. 54 to 60 Month 0ld

Female Children) on the Discontinuity per

100 Words Spoken of Three Individual Types

of Discontinuities and Their Total . . . . . . . . 34

IV Summary of the Mann-Whitney U Test for the Effect

of Age on the Discontinuities per 100 Words

Spoken of Three Individual Discontinuities

and Their Total . . . . . . . . . . . . . 34

$\mathrm{V}$ Comparison of Target Discontinuities Within

30 to 36 Month old Age Group . . . . . . . . . . 37

VI Comparison of Target Discontinuities Within 54 to 60

Month old Age Group ............. 37

VII Part Word Repetitions' Data in Past Investigations

on Normal Children's Speech . . . . . . . . . . . 40 
VIII Whole Word Repetitions' Data in Past Investigations on Normal Children's Speech . . . . . . . . . . 43

IX False Starts' Data in Past Investigations on Normal Children's Speech . . . . . . . . . . . . . . 46 


\section{CHAPTER I}

INTRODUCTION AND STATEMENT OF PURPOSE

\section{INTRODUCTION}

A goal of speech-language pathologists is to identify young children who exhibit an abnormal amount of disfluent speech. Early diagnosis is critical in order to begin clinical intervention or to monitor the children over time. There is, however, a lack of information available concerning the type or amount of discontinuities that occur in the speech of normal children. This normative data is needed in order to be able to differentially diagnose early childhood stuttering. Wexler and Mysak (1982) suggested that additional information on normal discontinuities would also aid in counseling parents, determining prognosis, and making recommendations regarding intervention.

Research into the area of normal discontinuities has shown that all individuals, adults and children, demonstrate discontinuities. These discontinuities may take the form of, but not be 1 imited to, sound and syllable repetitions, whole word repetitions, phrase repetitions, interjections, false starts, prolongations, and parenthetical remarks. Although the types of discontinuities and the frequency vary, discontinuities continue into adulthood but change in type (Starkweather, 1985). Starkweather has further proposed that normal speakers display different types of discontinuities depending upon their age. For example, young preschool children are more likely to produce part word 
repetitions than normal adults, and normal adults are more likely to produce parenthetical remarks, such as; "Do you understand?", than normal preschoolers. Starkweather, therefore, concluded that what differentiates an incipient stutterer from a normally disfluent individual is the type of discontinuity they display. Starkweather further states that "False starts are somewhat immature, repetitions are quite immature, and part word repetitions are very immature." The more immature discontinuities an individual uses that are inappropriate for their age, the more abnormal their disfluent behavior.

There is conflicting evidence in support of this theory when it is applied to preschool children (DeJoy and Gregory, 1985). DeJoy and Gregory have not found clear cut developmental trends in preschoolers' disfluent speech behavior but instead have found a high degree of variability. DeJoy and Gregory, however, have stated that studies of larger samples of normally disfluent children may reveal such developmental trends. This study will attempt to add additional information to the current literature on normal discontinuity in preschool children, and begin to establish the basis for future longitudinal studies.

\section{STATEMENT OF PURPOSE}

The purpose of this study was to compare the frequency of occurrence of specific discontinuities in 30 to 36 month old normal female children to normal 54 to 60 month old female children. Specifically, the discontinuities were categorized as follows: part word repetitions, whole word repetitions, and false starts. The discontinuities were observed while the child spontaneously interacted with an investigator in a clinical room. 
The following questions were addressed:

1) Do 30 to 36 month old normal female children differ in their total frequency of specific discontinuities when compared to normal 54 to 60 month old female children?

2) Do 30 to 36 month old normal female children demonstrate more part word repetitions than normal 54 to 60 month old female children?

3) Do 30 to 36 month old normal female children demonstrate more whole word repetitions than 54 to 60 month old normal female children?

4) Do 30 to 36 month old normal female children demonstrate more false starts than normal 54 to 60 month old female children?

\section{DEFINITION OF TERMS}

The following operational definitions should aid in understanding the language used in this investigation.

1) Discontinuity: The term discontinuity as defined by Starkweather (1985) is a more precise term than disfluency, and refers to more than just the absence of fluency during speech production; it includes; pauses, hesitations, whole and part word repetitions and any other break that interferes with the forward flow of speech.

2) Disrhythmic Phonation: The term disrhythmic phonation refers to audible or silent continuation of a sound or articulatory posture which is of such excessive duration as to interrupt the rhythmic flow of speech. The term prolongation is used interchangeably with disrhythmic phonation.

3) False Start: The term false start refers to instances in which the content of a phrase is modified or in which there is a grammatical modification (Starkweather, 1985). Changes in the 
pronounciation of a word, with the exception of the schwa, are also counted as false starts for the purposes of this study. False starts are also referred to as revision-incomplete phrases. Some studies have reported revisions and incomplete phrases separately, but reported separately they are not synonomous with false starts. The following is an example of a false start: "I was-I am going."

4) Fluency/Disfluency: The word fluency means flowing along and originally referred to the ease, quickness, and smoothness an individual spoke a second language. More specifically, an individual may be semantically, syntactically, pragmatically, and phonologically a fluent speaker. In stuttering terminology, speech fluency is speech that is produced with ease and is characterized by normal rate and continuity.

5) Incipient Stutterer: The term incipient stutterer refers to an individual who is beginning to demonstrate stuttering behavior that is not within normal limits. This type of individual will usually require intervention for the development of fluent speech, and probably will not recover spontaneously.

6) Incomplete Phrase: See false start.

7) Interjection: The term interjection, as defined by Johnson (1961) refers to extraneous sounds such as "uh" and "er" and "hmmm" and extraneous words such as "wel1" which are inserted within the flow of speech and are not part of the phrase or sentence.

8) Parallel Ta1k: As defined by Van Riper (1972) is an individual commenting on what a child is doing, perceiving, or feeling and also allowing moments of silence, while playing with the child to encourage the child to verbalize.

9) Parenthetical Remark: The term parenthetical remark refers 
to filler words which occur within an utterance. They add no additional contextual information; when spoken they provide the speaker with extra time to correct or process their thoughts or language (Starkweather, 1985). Examples of parenthetical remarks include: "Understand?", "Do you know what I mean?", and "I mean, I mean."

10) Part Word Repetition: The term part word repetition refers to repetitions of parts of words, either syllables or sounds, as in the examples; "d-dog" or "ta-table." No matter how many syllables or sounds may be repeated per word, only one discontinuity is credited. In the examples, "b-b-baby" or "b-baby" -- each word is considered one discontinuity.

11) Phrase Repetition: The term phrase repetition refers to repetitions of two or more words, for example: "and the, and the, and the baby cried."

12) Revisions: See false start.

13) Whole Word Repetition: The term whole word repetition; as defined by Johnson (1961), refers to unintentional repetitions of whole words, including words of one or more syllables. The following are examples of whole word repetitions: "I-I-I" and "going-going." 
CHAPTER II

REVIEW OF THE LITERATURE

NORMAL DISCONTINUITIES IN PRESCHOOL CHILDREN

Research in the area of stuttering has focused its attention on compiling normative data on the speech fluency of young children to aid identification of the incipient stutterer. Since the onset of most incipient stutterers is between the ages of 2 and 6 years, studies have investigated the speeth in normal young children to determine if children exhibit normal discontinuities. This information could then be compared to the speech of potential incipient stutterers to see if a stuttering problem exists.

\section{Historical Perspective}

There has been a history of studies investigating normal disfluencies in young children. In the $1930 \mathrm{~s}$ and $1940 \mathrm{~s}$ a number of studies were conducted at the University of Iowa, specifically focusing on the speech behavior of normal young children (Branscom, Hughes, and Oxtoby, 1955). Early studies by Branscom, Hughes, Oxtoby, (1955), Davis, (1939), and Johnson (1955) utilized 193 normal boys and girls with no history of stuttering; the children were between the ages of 2 and 5 years old. All five of the above studies analyzed the children's speech to determine what type of repetitions the children were demonstrating (i.e. syllable repetition, word repetition and phrase repetition). The results of these five normative studies showed that every subject 
demonstrated some degree of repetitiousness, showing that syllable, word, and phrase repetitions are a consistent, if not prominent, component in young children's speech. The studies did, however, find that repetitions tend to decrease in frequency with an increase in chronological age (Table I). Wendel Johnson (1961) summarized the early studies stating that a11 children demonstrate discontinuities at a young age. Johnson further reported that normal adults as well as children demonstrate discontinuities, but as children mature the types of discontinuities change.

Problems Observed in Earlier Studies

More recent investigations have questioned the results of these early studies. Studies of the 1930 s and $1940 \mathrm{~s}$ focused primarily on repetitions while disregarding the wide range of additional discontinuities, such as: prolongations, false starts, and verbal fillers. Additiona11y, early studies lacked electronic recording equipment which forced investigators to count discontinuities during the actual speech sampling (Wexler and Mysak, 1982; Yairi, 1981). Branscom, et al (1955) and Davis (1939) wrote out the remarks of the subjects verbatim at the time of sampling while Hughes, Oxtoby (Branscom, et a1, 1955) and Johnson (1955) employed a coding system at the time of speech sampling. This type of speech and fluency sampling has been questioned by recent investigators who question how accurate the data is. Another problem noted with early investigations was the small number of children used for each group. The small number of children appear to be inadequate for drawing valid conclusions. Additiona1ly, the earlier investigators did not conduct longitudinal samplings, which failed to 


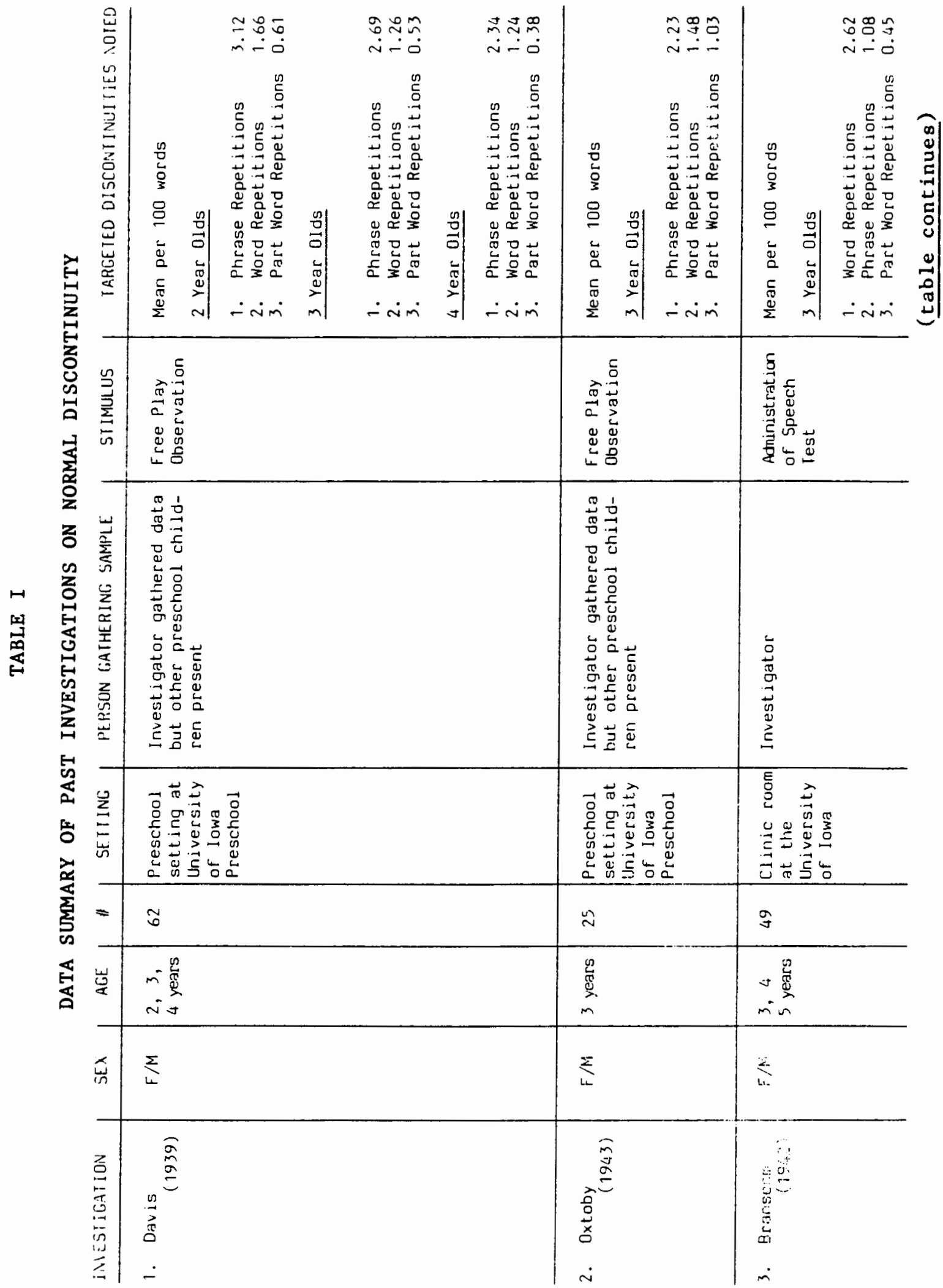




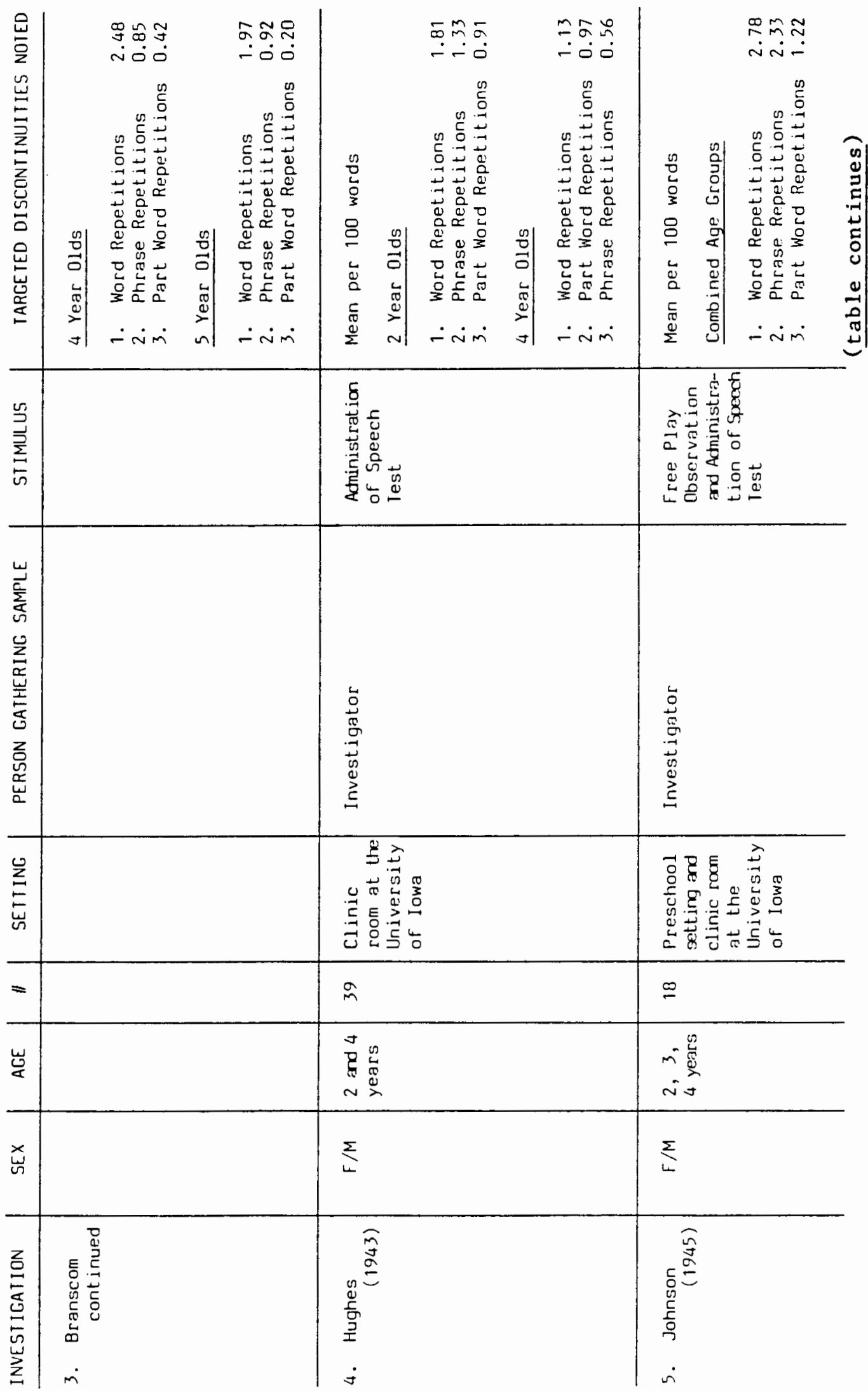



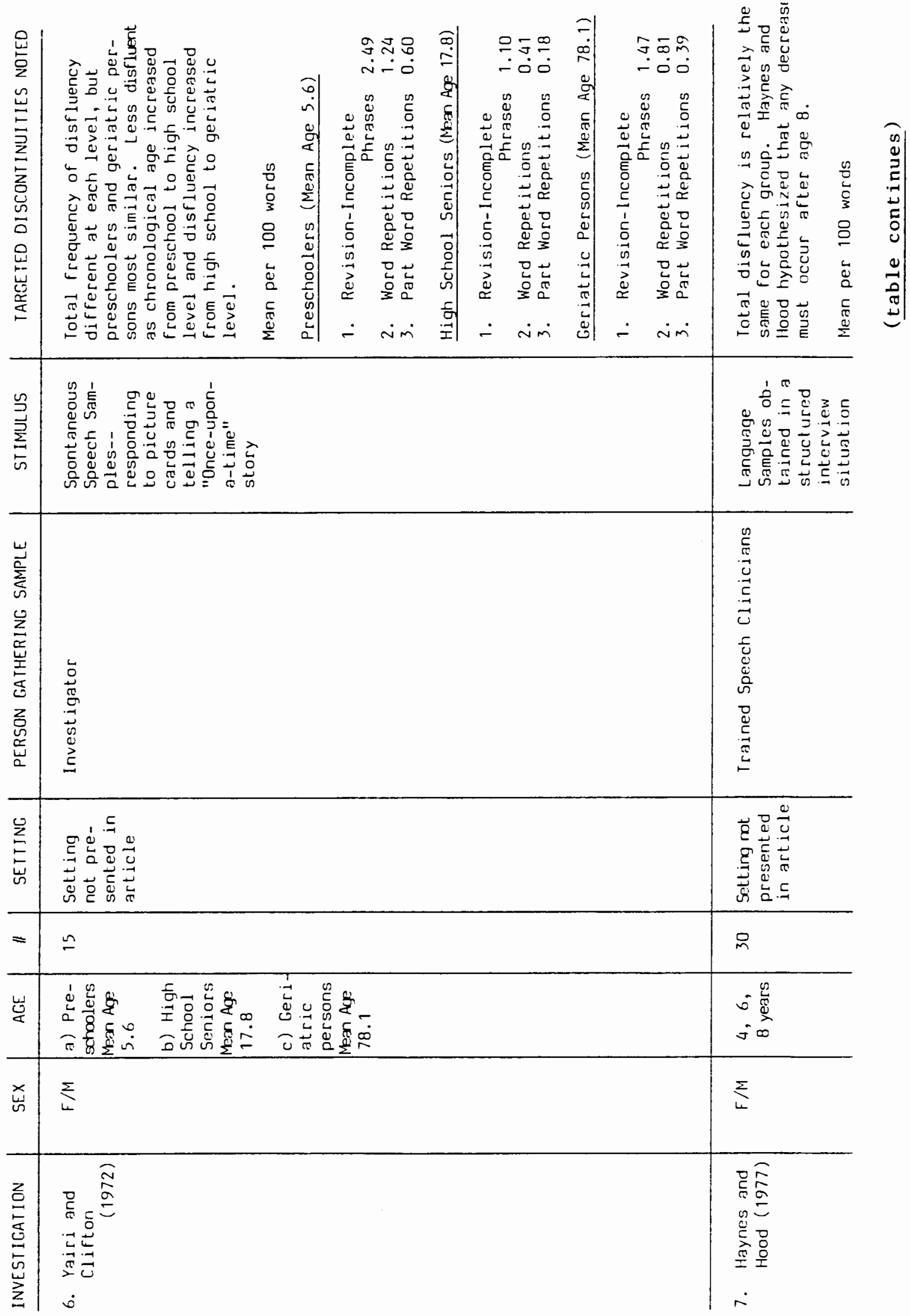


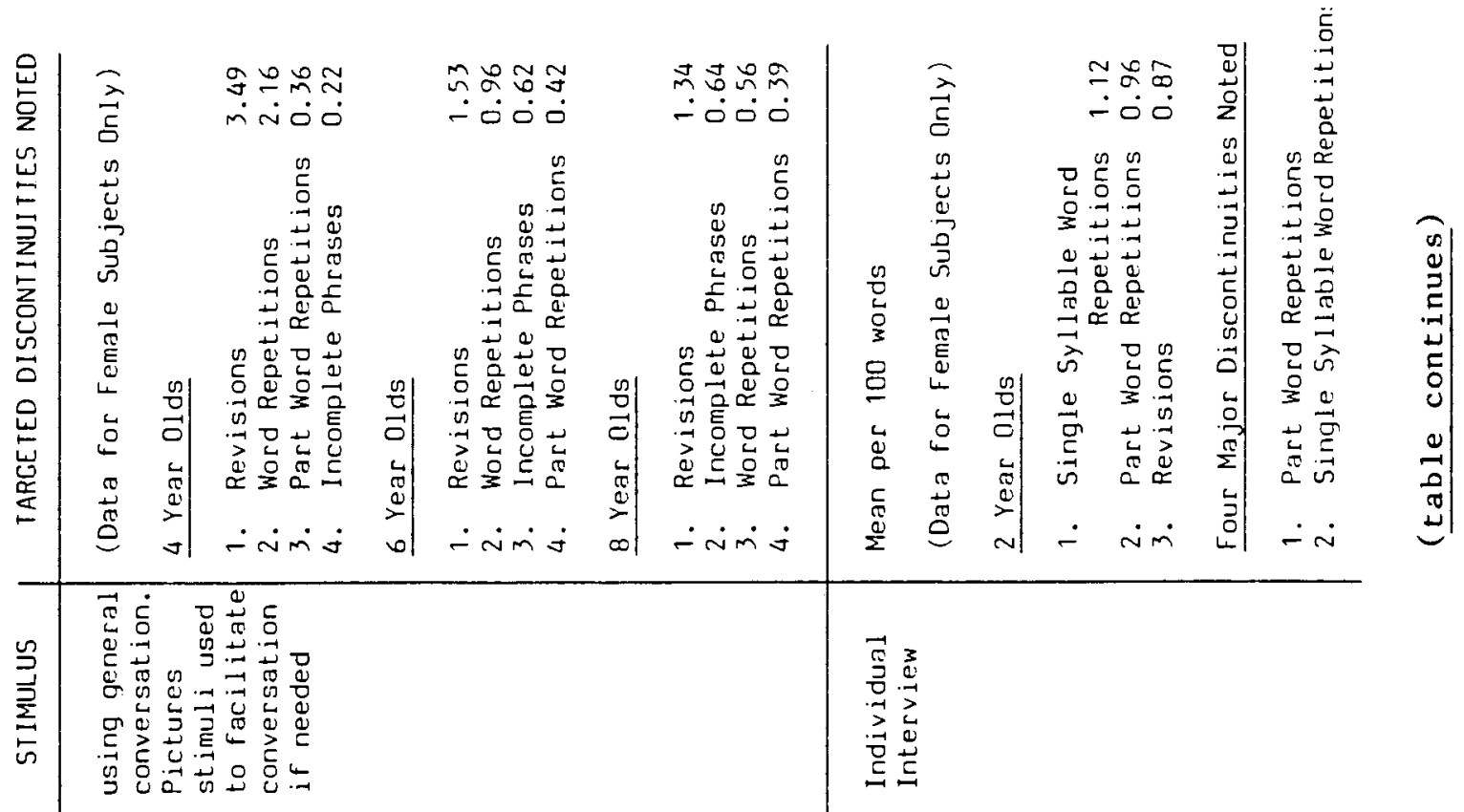

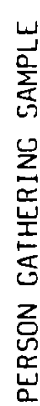

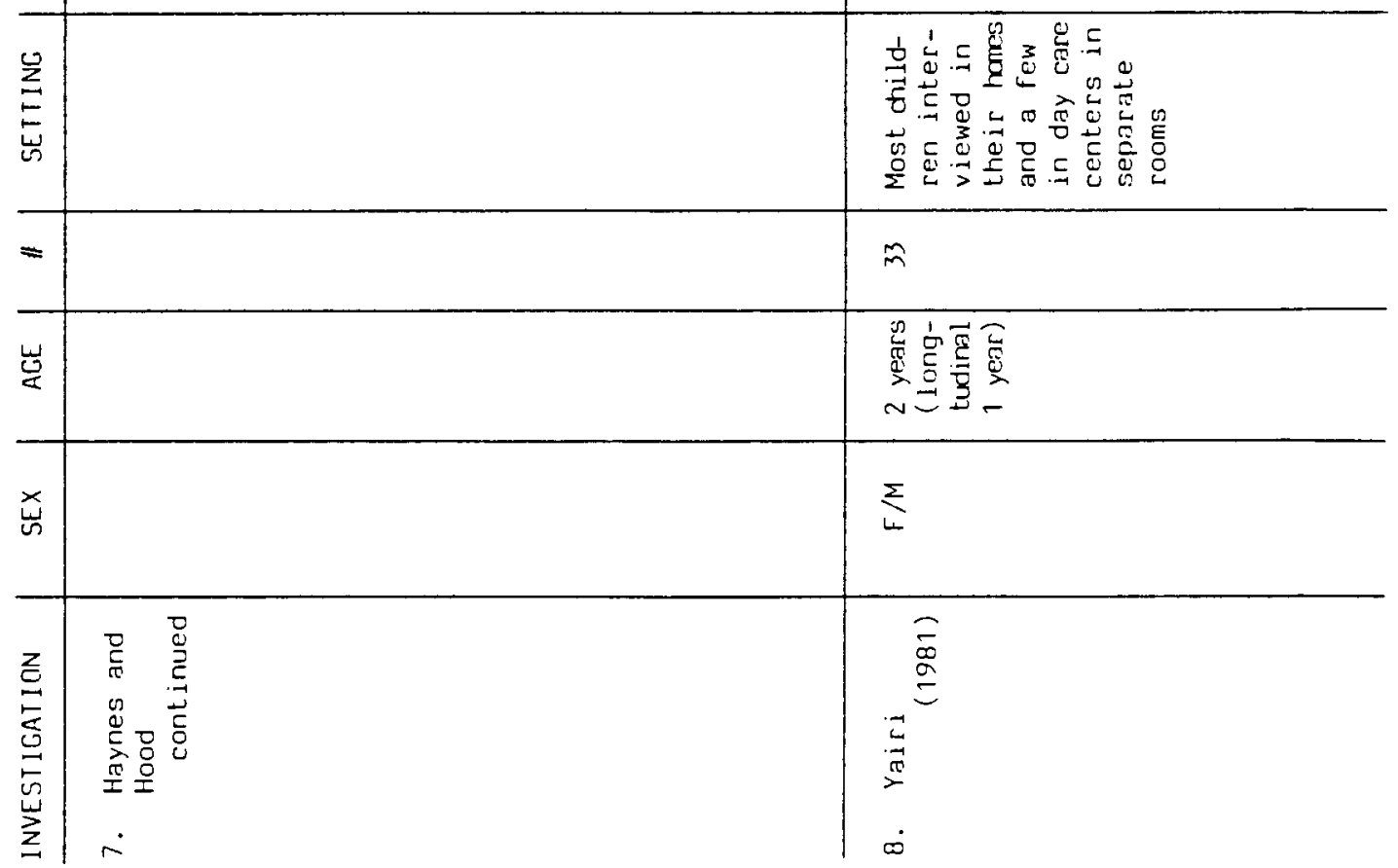




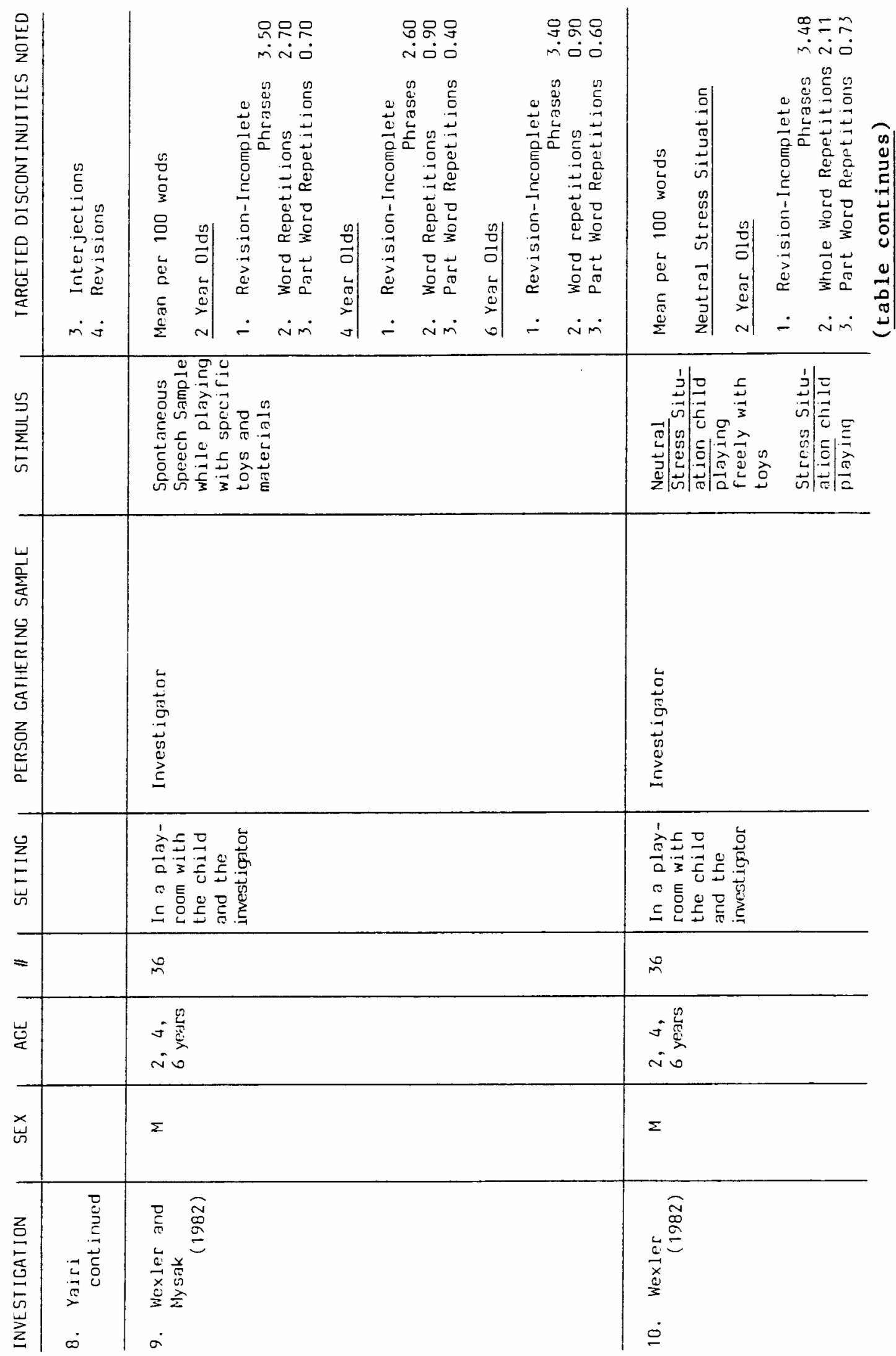




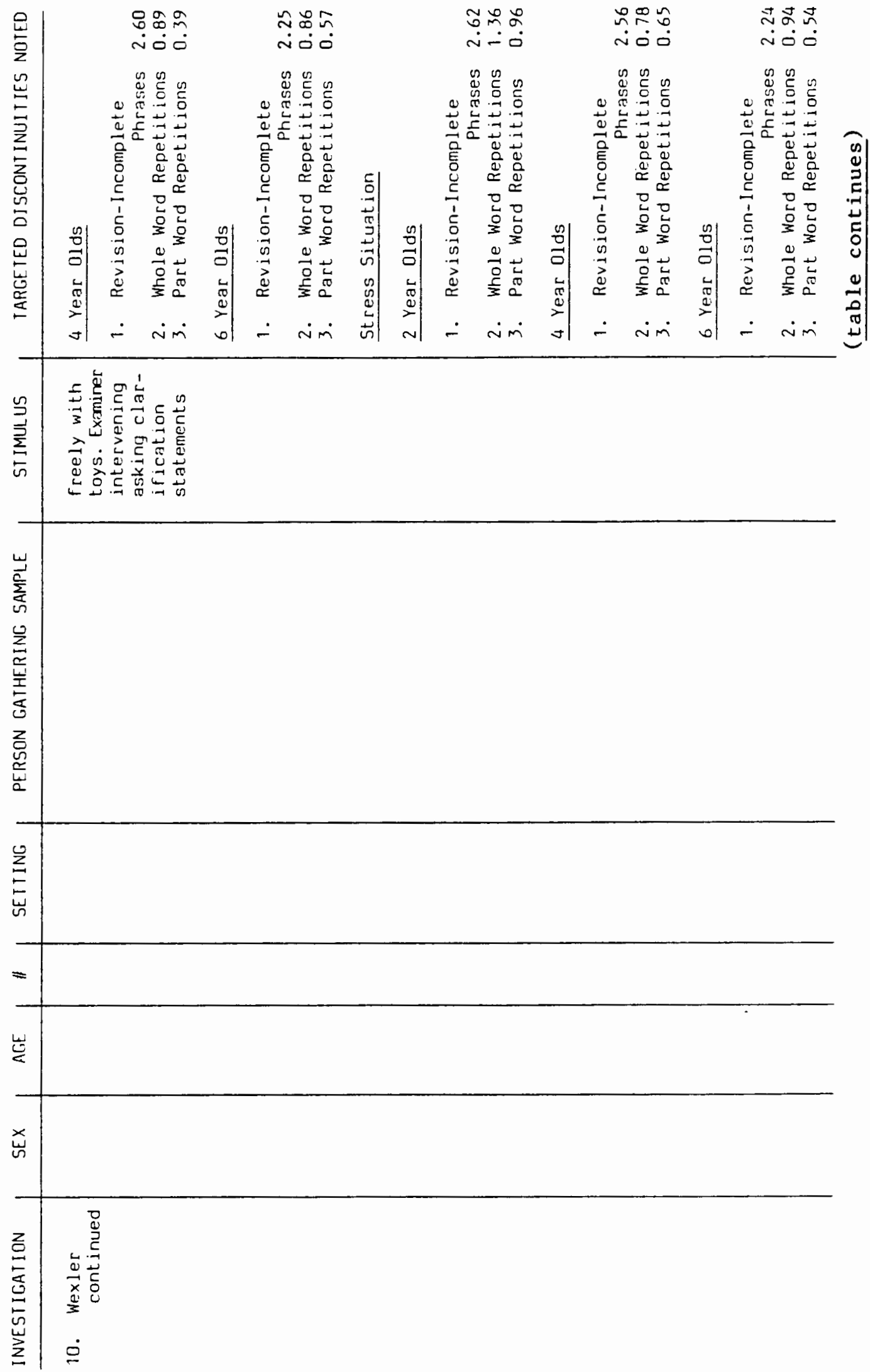




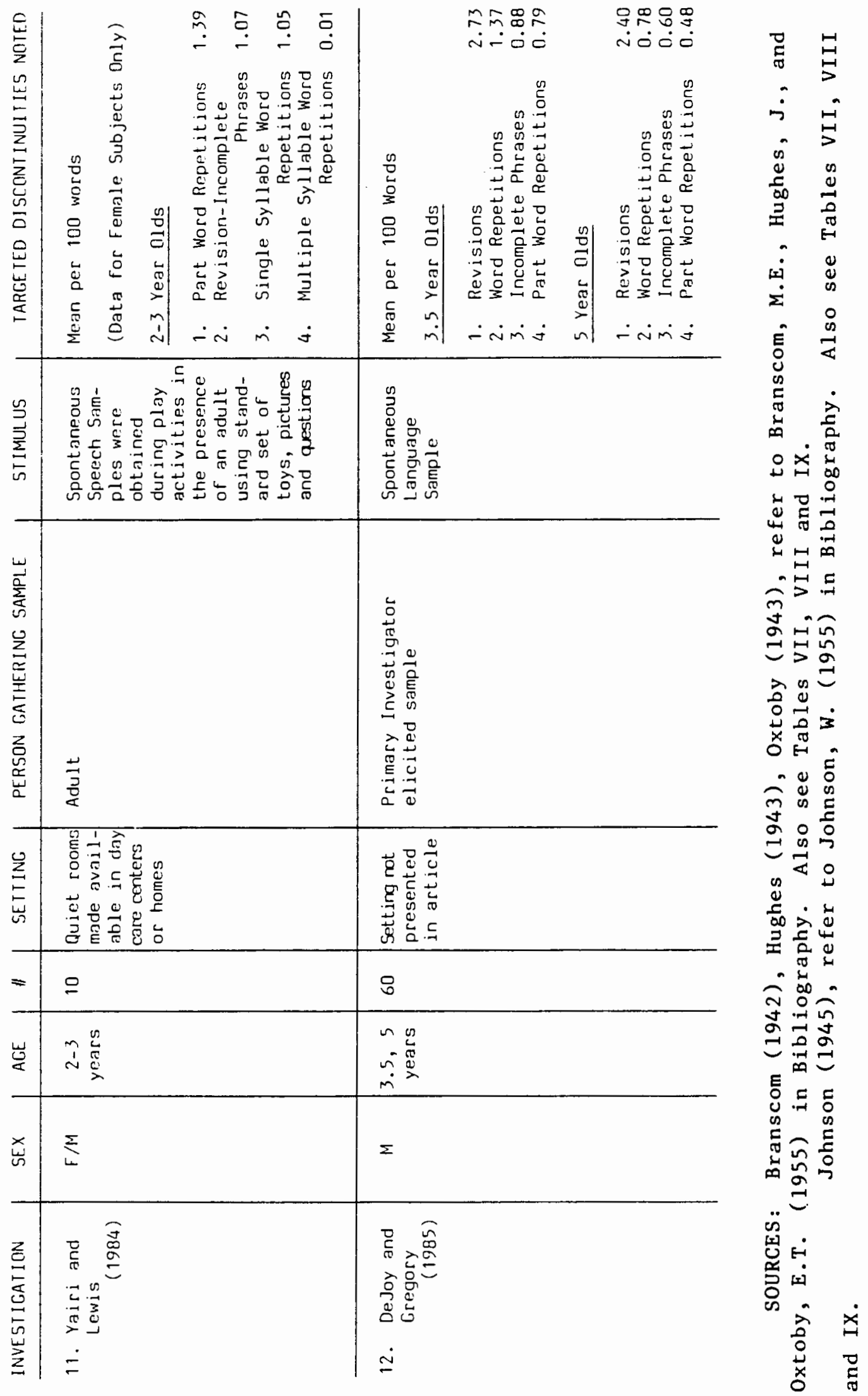


supply information about variations of speech behavior with the same children over time.

\section{Recent Investigations Concerning Normal Discontinuities}

Within the last ten years, investigators have become interested again in developing more reliable standardized norms concerning the frequency of disfluent speech behavior in normal children. These recent investigations have attempted to gather additional information about discontinuity characteristics of normal preschool children at discrete age levels in order to determine whether clear cut developmental trends exist in preschooler's speech. Recent investigations of preschool children's speech fluency have been more precise and more reliable than earlier studies. They have defined terms more specifically and have investigated a larger range of discontinuities than earlier studies.

Starkweather (1985) has reviewed recent studies (Haynes and Hood, 1977; Kowal, O'Conne11 and Sabin, 1975; Wexler and Mysak, 1982; and Yairi, 1981) and formed the hypothesis that as children grow older their speech is not more continuous, but instead the forms of discontinuity change. Starkweather uses the term discontinuity to describe pauses, hesitations, whole and part word repetitions and other breaks in the forward flow of speech. Starkweather states that this term is broader and more comprehensive than the term disfluency, which refers primarily to the continuity of speech production.

Starkweather (1985) reported that there is a direct relationship between age and the type of discontinuity demonstrated by normal individuals; immature discontinuities are replaced by more sophisticated discontinuities. Starkweather gives the example of parenthetical 
remarks as one type of discontinuity used by adult speakers. The occurrence of some forms of discontinuities at older ages, such as part word repetitions, are representative of immaturity. Starkweather further states that nFalse starts are somewhat immature, repetitions are quite immature, and part word repetitions are very immature." However, Starkweather has drawn these conclusions from some studies that investigated children between the grade levels of kindergarten through high school and did not specifically focus on preschool children.

Yairi (1981) conducted a longitudinal study that focused on normal preschool children's speech continuity. Yairi's study is the only longitudinal study completed to date and it was for a very limited time period, one year. He followed a group of thirty-three 2 year olds, eighteen girls and fifteen boys, over the course of one year. Yairi observed the children three times during the year. He found that the children displayed all types of discontinuities although the frequency of occurrence of some types of discontinuities was very rare. Primarily, four major discontinuity types were noted in the children's speech: part word repetitions, single-syllable word repetitions, interjections and revisions. These four discontinuity types constituted 76 percent of the total discontinuities demonstrated by this group. Yairi also found that during the year, there were extreme fluctuations in the frequency of discontinuities. From the trends Yairi observed, he concluded that continuity of speech did not follow a predictable developmental course in 2 year old children; he also concluded that the means of his study were not an adequate representation of central tendency. Another study by Yairi and Lewis (1984) observed ten 2 and 3 year olds diagnosed by parents to have begun stuttering for periods of two 
months previously and ten matched normally speaking children, five boys and five girls for each group. They gathered 500 syllable samples and found that the normal 2 and 3 year olds demonstrated interjections, revision-incomplete phrases, and part word repetitions more than any other types of discontinuities. Although Yairi and Lewis reported that the normally speaking 2 and 3 year olds exhibited all types of discontinuities, certain types were very rare. This study further supported Yairi's 1981 findings with similar data concerning the frequency of occurrence of part word repetitions, interjections and revisions in 2 year old speech.

In the 1981 study, Yairi classified revisions separately from incomplete phrases and did not even address incomplete phrases. In the 1984 study, Yairi classified revisions and incomplete phrases together; the data, however, from both studies on revisions is very similar. The term revision-incomplete phrase is a synonym for the term false start that Starkweather (1985) uses.

Yairi and Clifton (1972) investigated the frequency of discontinuities in three groups of fifteen nonstuttering subjects. The three groups were preschool children, high school seniors, and geriatric patients. Spontaneous speech samples were elicited from the forty-five subjects using story telling techniques and by responding to picture cards. Results of this study showed that the preschool group was the most discontinuous group with a mean of 7.65 discontinuities per 100 words. Yairi and Clifton's preschool children had a mean age of 5 years 6 months. The geriatric group was the next most discontinuous group with a mean of 6.29 discontinuities per 100 words and the high school seniors were the least discontinuous with a mean of 3.83 discontinuities 
per 100 words. The results from this study only in part support Starkweather's (1985) hypothesis by showing that the frequency of occurrence of part word repetitions decreased from those obtained by 2 and 3 year olds in other Yairi studies, while whole word repetitions stayed relatively the same as those results presented in the 1981 and 1984 investigations. The frequency of occurrence of revision-incomplete phrases, however, increased with older preschool children when compared to the results of Yairi's other studies dealing with 2 and 3 year olds. Additionally the data does not support Starkweather's hypothesis that as children grow older their speech is not more continuous but instead the forms of discontinuity change. Yairi and Clifton's data reported that the frequency of occurrence of discontinuity decreased substantially between preschool and high school and then increased to almost preschool level, with similar types of discontinuities, by the geriatric level.

Wexler and Mysak's 1982 study also investigated normal preschool children. Wexler and Mysak studied the fluency characteristics of thirty-six nonstuttering males aged 2, 4, and 6 years of age. Wexler and Mak obtained speech samples by having each child talk with an investigator in a playroom, with a set of standard toys available for the child to play with. Wexler and Mysak found that certain disfluency types occurred more frequently than do others within each age group. The two most frequently occurring discontinuity types at each age level were revision-incomplete phrases and interjections. Phrase repetitions and word repetitions followed in terms of frequency for 2 year olds and the least occurring types of disfluency for the 2 and 4 year olds were part word repetitions. Disrhythmic phonations, part word repetitions, 
whole word repetitions (single syllable), and phrase repetitions were among the least frequently occurring discontinuity types for the 4 and 6 year olds.

An analysis of variance and pairwise comparison of means showed that 2 year olds had significantly higher discontinuity frequencies for word repetitions and phrase repetitions than did either the 4 or 6 year olds. It was also found that the 2 year olds had a higher frequency of disrhythmic phonations than did the 6 year olds. These results support, in part, Starkweather's (1985) hypothesis that immature children demonstrate more whole word repetitions than older children, in that the study showed that 2 year olds had significantly higher discontinuity frequencies for word repetitions than did the other two groups. However, the fact that the 2 year olds' least frequently occurring discontinuity type was part word repetitions did not support Starkweather's hypothesis.

Wexler and Mysak's (1982) results on frequency of occurrence of revision-incomplete phrases show a significantly higher frequency for the 2, 4, and 6 year olds than previous studies mentioned (Yairi and C1ifton, 1972; Yairi, 1981; Yairi and Lewis, 1984). Wexler and Mysak's study showed that the frequency of occurrence of revision-incomplete phrases decreased from a mean of 3.5 per 100 words for 2 year olds to 2.6 per 100 words for 4 year olds and then increased to 3.4 per 100 words for 6 year olds. These results do not support Starkweather's (1985) hypothesis that part word repetitions are quite immature and whole word repetitions are somewhat immature and false starts are less immature. These results support his hypothesis in that revision-incomplete phrases occurred more than any other discontinuity type and was 
highest occurring among 2 year olds. Starkweather's hypothesis would hypothesize that revision-incomplete phrases would have had a higher frequency of occurrence with 4 year olds and even a higher yet occurrence with 2 year olds.

Wexler and Mak (1982) summarized their study by stating that certain discontinuity types occur more frequently in the speech of each different age group. Wexler and Mysak also stated that the total frequency of discontinuties that occurred in each group's speech did not vary significantly although the frequency of occurrence of specific discontinuities did vary among age levels studied. They concluded their study by reporting their data supported the concept of developmental changes in discontinuity. This conclusion supports Starkweather's (1985) hypothesis that the total frequency of discontinuity does not increase as a child grows older but rather the specific types of discontinuities demonstrated by each age level change.

DeJoy and Gregory's 1985 preschool study provided further support to Starkweather's (1985) hypothesis. DeJoy and Gregory investigated sixty non-stuttering males, 3 years, 6 months to 5 years of age, and studied their speech during spontaneous conversation tasks with standard pictures and toys. DeJoy and Gregory reported that the younger children displayed significantly more frequent part word repetitions, word repetitions, phrase repetitions, incomplete phrases and disrhythmic phonations. The older children demonstrated more grammatical pauses. Grammatical pauses can be defined as silent pauses that occur at such grammatical junctures as: immediately preceding coordinating or subordinating junctions (DeJoy and Gregory, 1985). DeJoy and Gregory concluded from this study that certain types of discontinuities decrease 
substantially with an increase in chronological age, while others decrease only slightly and some types even show an incresse. DeJoy and Gregory further sumarized their data stating that the total frequency of occurrence of discontinuities decreased with an increase in chronological age.

DeJoy and Gregory's (1985) investigation supports Starkweather's (1985) hypothesis, concerning maturity and the type of discontinuity demonstrated by showing that the younger group of children demonstrated more repetitions, and as age increased less repetitions were demonstrated. The data also supported Starkweather's theory that younger children would demonstrate more false starts than older children since the data showed that the younger group of children had a somewhat higher frequency of occurrence of revisions than the older group. It should be noted although, that DeJoy and Gregory classified revisions and incomplete phrases separately.

Haynes and Hood's (1977) study evaluating discontinuities in thirty nonstuttering elementary school children in three different age groups--4, 6, and 8 year old children--further supported Starkweather's (1985) theory. Language samples were obtained during a structured interview situation. The samples were then analyzed for the occurrence of eight types of discontinuities. The results indicated that the 4,6 , and 8 year olds did not differ significantly in the total frequency of discontinuity per 100 words, although the discontinuity subtypes demonstrated by the different age groups shifted significantly. Haynes and Hood also found that interjections significantly increased between the ages of 4 and 8 , however, word repetitions exhibited a noticeable downward shift as chronological age increased. Another significant finding 
of this investigation was that part word repetitions occurred less than whole word repetitions, interjections and revisions.

\section{SUMMARY}

The studies previously discussed have shown inconsistencies in their results. These inconsistencies among investigations on preschooler's discontinuities are due to several factors. One factor is the difference in the collections of the samples and analysis of the samples (DeJoy and Gregory, 1985). For example, in some investigations revisions and incomplete phrases were classified separately (DeJoy and Gregory, 1985; Haynes and Hood, 1977; Yairi, 1981) while other investigations classified them together. The different classification systems affect the data reported concerning the frequency of occurrence of each type of discontinuity, and is one main reason for the discrepancies among studies. Another reason for the variability reported in the studies is the differences in how the samples were collected. Some samples were collected in spontaneous play situations with the investigator (Yairi and Lewis, 1984) while others collected their samples in interview situations with the child (Haynes and Hood, 1977). Not enough research has been done in this area to determine whether or not different sampling techniques affect the children's frequency of occurrence of discontinuities. It should also be noted that some investigations were collected in the home (Yairi, 1981) while others occurred in a playroom in the clinic (Wexler and Mysak, 1982). Again, not enough research has been done with preschool children to determine whether changes in the environment where the samples are collected affects the children's discontinuities. Another factor that accounts for some of 
the discrepancies among the investigations is due to the fact that preschool chidren show a high degree of variability in their speech in regards to discontinuities (Yairi, 1981), and in order to compensate for this, studies must be designed to investigate larger numbers of preschool children, in both stratified and longitudian1 studies. In summarizing the findings of recent investigations several consistent patterns have emerged. DeJoy and Gregory (1985) stated in their review of the literature that all studies showed a high degree of variability, and therefore concluded with such variability the discovery of developmental trends may only be discovered with investigations utilizing larger samples of children. They also summarized their review of the literature by showing that as of yet no clear cut developmental trends in the discontinuity of preschool children have been discovered, due in part to the variability of discontinuities in the speech of preschool children.

Recent investigations have also consistently shown that preschool children evidence higher frequencies of interjections and revisionincomplete phrases than all other categories of discontinuities (DeJoy and Gregory, 1985).

Investigations dealing with both preschool males and females have also consistently found that there are similar patterns of discontinuity for both males and females, one group does not appear to demonstrate significan1ty more discontinuities than the other (Haynes and Hood, 1977).

Variations in the results of investigations are primarily observed when absolute frequencies of discontinuities are compared among investigations. These variations in data influenced whether investigators 
summarized their investigations by finding less discontinuity with advancing age or an increase in discontinuity at certain ages or even the same total frequency of discontinuities at all ages studied Further investigations are needed to specifically focus on discontinuities to determine whether or not developmental trends do exist in the speech of preschool children. The studies should involve a large number of subjects and be designed to include both stratified and longitudinal investigations. 


\section{CHAPTER III}

METHODS

SUBJECTS

Twenty normal female subjects were utilized for this study. Ten female children between the ages of 30 to 36 months $(\bar{x}=33.7)$, and ten female children between the ages of 54 to 60 months $(\bar{x}=57.7)$ were involved in this investigation. The subjects were located in various nursery schools and daycare centers in Portland, Hillsboro, and Milwaukie, Oregon. No attempt was made to control for socioeconomic level. Subjects, however, were recruited from six daycare centers and nursery schools to balance selection to any one area. Eight of the children did not attend preschool and one of the eight children attended kindergarten.

The subjects are selected randomly from all children fitting the selection criteria. To be included in this study the children had to meet the following criteria:

1) The parent or primary caregiver signed and returned a release form giving permission for the child to participate in the study (Appendix A).

2) The child had at least 75 percent speech intelligibility as calculated for a 100 word, out of context, speech sample.

3) The child used at least a Mean Length of Response (MLR) of 2.5. The total number of words was divided by the total number of 
utterances to determine the MLR of a 100 word spontaneous speech sample.

4) The child did not have a previously known mental handicap, neurological problem or physical handicap.

5) The child spoke English as a primary language in the home.

6) The child did not have a history of middle ear infection.

7) The child did not have a cold at the time of the recording session.

8) The child between 54 to 60 months passed a puretone hearing screening test at $25 \mathrm{db} \mathrm{HL}$ at the following frequencies: $500 \mathrm{~Hz}, 1000$ $\mathrm{Hz}, 2000 \mathrm{~Hz}, 3000 \mathrm{~Hz}$, and $4000 \mathrm{~Hz}$.

9) The child must not have been considered to have or ever been counseled for fluency problems.

10) The child was judged to be able to attend to one low stress task for 15 minutes.

A puretone hearing screening was not used for criteria selection of the 30 to 36 month old children due to the age of the subjects in that group. Using the criteria that these children did not have a history of middle ear infection or a cold at the time of the recording session adequately screened out children who might possibly have some degree of hearing $105 \mathrm{~s}$.

\section{INSTRUMENTATION}

A Peabody Picture Vocabulary Test - Revised (PPVT-R) developed by Lloyd Dunn (1981), which tests the child's receptive vocabulary was administered to each child during a pre-assessment task. The results of this test were not included in this study but will be used for future studies. 
Each parent or primary caregiver completed a Parent Permission form and a questionnaire addressing developmental, speech, medical, and familial history (Appendix B) prior to the recording session. This form was developed at Portland State University Speech and Hearing Clinic and will also be used for future studies in this research area.

\section{PROCEDURES}

Each parent or primary caregiver was informed that the purpose of the study was to observe and record normal young children's speech, specifically looking at their fluency. Additionally, each parent was told that they could withdraw their child from the study at any time.

A pre-assessment procedure was conducted with each child before the actual recording session, by the investigator in their respective nursery schools and daycare centers or at the home or clinic. The preassessment procedure included an assessment of the child's Mean Length of Response and articulation intelligibility, through a brief taped conversation with the investigator. A PPVT-R (Dunn, 1981), was also administered to each child during the pre-assessment procedure for purposes of future research. The group of children between 54 to 60 months were also given a puretone hearing screening test at $25 \mathrm{~dB}$ HL at the following frequencies: $500 \mathrm{~Hz}, 1000 \mathrm{~Hz}, 2000 \mathrm{~Hz}, 3000 \mathrm{~Hz}$, and $4000 \mathrm{~Hz}$.

Spontaneous speech samples were then obtained for each subject in a clinical setting at Portland State University. Each session was conducted in a carpeted clinical room, with only the child and the investigator. Video equipment was place adjacent to the control room where the subjects were taped via a one-way mirror and sound 
amplification system. All sessions were video taped with a Panasonic Single Camera Recording System. The child was video taped interacting with the investigator for 15 minutes. The investigator elicited a spontaneous speech sample through use of standard toys and open ended questions (Appendix C). To elicit the sample, a covered box of toys was presented and each child was encouraged to guess the content. After a few minutes the child was told to open the box and explore the contents while the investigator used parallel talk to stimulate verbalizations by the child. If the child was not spontaneously verbalizing following eight minutes of play, the toys were returned to the box and the investigator asked the child open ended questions for the remaining seven minutes.

SCORING AND DATA ANALYSIS

The subjects' speech samples were transcribed verbatim from the recordings by the investigator, who then identified and classified specific discontinuities. The discontinuities were classified according to three categories: part word repetitions, whole word repetitions, and false starts. The frequency of occurrence was calculated for each type of discontinuity per 300 word sample. The disfluencies were calculated to find individual and group data.

The mean and standard deviation of the discontinuities was calculated for each type of target discontinuity and the total of the target discontinuities. A one way analysis of variance for independent means was performed to evaluate the degree of difference between all types of targeted discontinuities in the two different age groups. In this case, the equivalent t-test was applied since there were only two 
factors. The assumptions for these tests state that the populations under consideration must be independent and normally distributed with equal variances. To do a test of equality of variance the F-test was applied to each of the four targets. If the F-test for equality of variances indicated no reason to doubt equality the $\underline{t}$-test was used and tested at the $\propto=.05$ level; d.f.=18. If there was reason to doubt the variance equality assumption, a d.f. $=9$ was used instead of a d.f. $=18$.

The difference in discontinuities within each age group was also calculated using a mean (ANOVA) method.

\section{REL IAB IL ITY}

In order to assess investigator reliability in identifying and counting discontinuities, six samples of ten utterances each, three from each age group, were randomly selected from all video taped recordings. These segments were transcribed verbatim and the transcripts were given to a second year graduate student in the Portland State University Department of Speech Communication, who extracted ten episodes from each of the six transcripts and formed content transcripts. Content transcripts can be defined as the basic information of an utterance provided by the child deleting any type of discontinuity, such as: false starts, part word repetitions or prolongations (Appendix D). These content transcripts were then given to two other second year graduate students in the Portland State University Department of Speech Communication (Appendix E). A technician then played the corresponding segment of the video tape that matched the content transcripts. The technician then showed the reliability raters all ten episodes at once while the raters observed the episodes in their entirety. The technician then played the 
video tape segments again only showing the reliability raters one episode at a time. The raters were responsible for filling in all missing parts of the transcripts, including words that had been deleted and all discontinuities:

1) Raters are only responsible for identification of whole word repetitions, part word repetitions, and false starts.

2) Identify part word repetitions by marking pw above the part word repetition, and whole word repetitions by marking ww over the whole word repetition.

3) No matter how many times a whole word or part word is repeated it is only credited as one discontinuity.

4) An episode may have a combination of any of the three discontinuity types, and should be credited as separate discontinuities if this occurs.

Examples: Ky-Kyle Kyle - 1 part word repetition, 1 whole word repetition Th-The-The table-the tablet - 1 part word repetition, 1 whole word repetition and 1 false start

5) Repetitions of the first part of a contraction such as: "itit's" and "I-I'm" should be credited as a part word repetition since the contraction functions as a single word for the young child and was calculated as one word when determining the 300 word count for the initial transcripts.

6) Identify false starts by marking fs above the false start in the episode.

7) Whole words that are repeated. but are separated by interjections are not credited as whole word repetitions. 
Example: They uh uh They

8) Interjection repetitions are not credited as either part word repetition or whole word repetitions.

A training session was conducted prior to the actual reliability testing by the investigator, using the same procedures outlined above.

A Sander's Agreement Index (Sander, 1961) formula was used to calculate the frequency of occurrence scores of the two observers in comparison to the investigator's original findings, on the six samples. The index of agreement was 98.3 percent. Instances of discrepancies were resolved through repeated simultaneous listening and viewing of the video tapes.

Two of the six content transcripts were then randomly selected by the video technician. Discontinuities were then classified by the investigator and the two graduate students one hour after the initial reliability testing using the same procedures as were used for the initial reliability testing. A perfect agreement of 1.0 was achieved for the investigator and the two graduate students for intrajudge reliability. 
CHAPTER IV

RESULTS AND DISCUSSION

\section{RESULTS}

This study was conducted to determine if 30 to 36 month old female children differ in their frequency of occurrence of specific discontinuities when compared to 54 to 60 month old female children. Specifically, the discontinuities were categorized as follows: part word repetitions, whole word repetitions, and false starts. Ten 30 to 36 month old and ten 54 to 60 month old normal female children's spontaneous speech samples were utilized to compare discontinuities in this study.

The first question asked was: Do 30 to 36 month old normal female children differ in their total frequency of specific discontinuities when compared to normal 54 to 60 month old female children? The mean for the 30 to 36 month old group was 3.53 discontinuities per 100 words and 2.73 discontinuities for the 54 to 60 month old group (Table II). The mean of the total frequency of specific discontinuities were compared for the two groups, using a one-way analysis of variance, resulting in a t-value of 0.87 (d.f.=18). Although the 30 to 36 month old age group demonstrated more total discontinuities when compared to the 54 to 60 month old group, a statistically significant difference was not shown at the 0.05 level of probability (Table III). 
TABLE II

SUMMARY OF MEANS AND STANDARD DEVIATIONS FOR THREE

INDIVIDUAL TYPES OF DISCONTINUITIES PER 100

WORDS SPOKEN FOR 30 TO 36 MONTH OLD AND

54 TO 60 MONTH OLD FEMALE CHILDREN

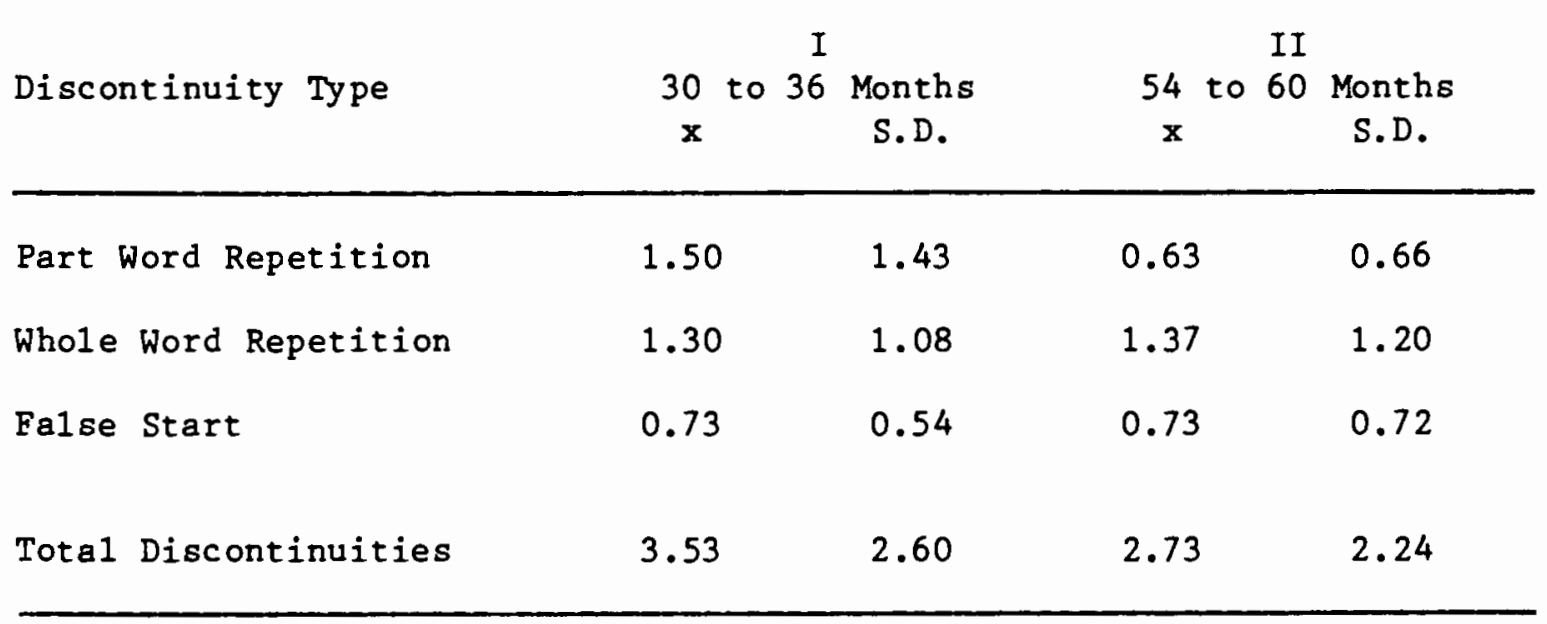

On further investigation of this data it was decided that a MannWhitney $U$ test (Silverman, 1985) be done for total frequency of specific discontinuities. This was done because the Mann-Whitney test is more powerful than the mean test used, it considers the rank value of each observation rather than simply its location with respect to the combined mean, and this uses more of the information in the data (Silverman, 1985). The Mann-Whitney is not affected by a wide range of outlying scores. The results of this analysis yielded a $z$-value of -1.13 , this value was not significant at the 0.05 level of probability (Table IV). The second question asked was: Do 30 to 36 month o1d normal female children demonstrate more part word repetitions than norma1 54 to 
TABLE III

SUMMARY OF ONE WAY ANALYSIS OF VARIANCE FOR THE EFFECT

OF AGE (30 TO 36 MONTH OLD VS. 54 TO 60 MONTH OLD

FEMALE CHILDREN) ON THE DISCONTINUITY PER

100 WORDS SPOKEN OF THREE INDIVIDUAL

TYPES OF DISCONTINUITIES AND

THEIR TOTAL

\begin{tabular}{lccc} 
Discontinuity & $t$ & d.f. & p \\
\hline Part Word Repetition & 1.75 & 9 & 0.05 \\
Whole Word Repetition & -0.04 & 18 & 0.05 \\
False Start & 0.00 & 18 & 0.05 \\
Total Target Discontinuities & 0.87 & 18 & 0.05 \\
\hline
\end{tabular}

TABLE IV

SUMMARY OF THE MANN-WHITNERY U TEST FOR THE EFFECT

OF AGE ON THE DISCONTINUITIES PER 100 WORDS

SPOKEN OF THREE INDIVIDUAL DISCONTINUITIES

AND THEIR TOTAL

Target Discontinuity

$\underline{\mathrm{z}} \quad \mathrm{p}$

Part Word Repetition

$-2.04$

$0.05 *$

Whole Word Repetition

$-0.56$

0.05

False Start

$-0.94$

0.05

Total Target Discontinuities

$-1.13$

0.05

* Significant at 0.05 level of probability 
60 month old femele children? Children from the 30 to 36 month old group exhibited a mean of 1.50 part word repetitions per 100 words while the 54 to 60 month o1d group exhibited a mean of 0.63 part word repetitions per 100 words (Table II). The means for the two groups were compared using a one-way analysis of variance, resulting in a $\underline{t}-v a l u e$ of $1.75\left(d_{. f .}=9\right)$. The part word repetition analysis indicated that the mean for the 30 to 36 month old females was significantly more than the 54 to 60 month old group's mean at a level of $0.05<\propto<0.10$. The leve1 of significance, $\alpha$, would have been less than 0.05 if the variances were not significantly different. Therefore half the number of the degrees of freedom was used to compensate for the differences in variances (Table III). The results of the Mann-Whitney $U$ test (Silverman, 1985) yielded a $\underline{\text { z-value of }}-2.04$. The results of this analysis was also significant at the 0.05 level of probability (Table IV).

The third question asked was: Do 30 to 36 month old normal female children demonstrate more whole word repetitions that 54 to 60 month old normal female children? The 30 to 36 month old age group demonstrated a mean of 1.30 whole word repetitions per 100 words while the 54 to 60 month old group demonstrated a mean of 1.37 whole word repetitions per 100 words (Table II). The means of the whole word repetitions were compared resulting in a t-value of -0.04 (d.f.=18) (Table III). The $\underline{t}-$ value demonstrated that the difference between these two means was not significant at the 0.05 level of probability. The Mann-Whitney $U$ test (Silverman, 1985) yielded a Z-value of -0.94 , this value was not significant at the 0.05 level of probability (Table IV). Female children from the 30 to 36 month old group did not demonstrate significantly more whole word repetitions than the 54 to 60 month old group. 
The fourth question asked was: Do 30 to 36 month old normal female children demonstrate more false starts than 54 to 60 month old normal female children? Children in the 54 to 60 month old group exhibited a mean of 0.73 false starts per 100 words while the 30 to 36 month old age group also exhibited a mean of 0.73 false starts per 100 words (Table II). The comparison of these two means resulted in a tvalue of $0\left(d_{.} f_{.=18}\right.$ ). The Mann-Whitney U test (Silverman, 1985) resulted in a Z-value of -1.13 , this value was not significant at the 0.05 level of probability.

These results indicate that no statistically significant differences exist between whole word repetitions and false starts made by the 30 to 36 month old children and the 54 to 60 month old children. Results do indicate, however, the existence of a statistically significant difference between part word repetitions in the 30 to 36 month old children and the 54 to 60 month old children.

A comparison of two discontinuities within each age group was also done for purposes of future research. The data revealed that the only statistically significant difference in the 30 to 36 month old age group was the comaprison of part word repetitions to false starts, resulting in a t-value of $2.56\left(d_{.} .=9\right)$ indicating a significant difference at the 0.05 level of probability (Table V). This data indicates that the number of part word repetitions was significantly different than the number of false starts demonstrated by this age group. A statistically significant difference was also found when comparing part word repetitions to whole word repetitions within the 54 to 60 month old age group. A t-value of $-3.06(d, f .=9)$ at the 0.05 level of probability was found. This data indicated that 54 to 60 month old children in this study 
TABLE $\nabla$

COMPARISON OF TARGET DISCONTINUITIES WITHIN

30 TO 36 MONTH OLD AGE GROUP

\begin{tabular}{lccc}
\hline & $t$ & & \\
\hline Discontinuity Comparison & $\underline{\text { d.f. }}$ & $\mathrm{p}$ \\
\hline Part Word Repetition--False Start & 2.56 & 9 & $0.05 *$ \\
Whole Word--Part Word Repetition & -0.30 & 9 & 0.05 \\
Whole Word Repetition--False Start & 1.80 & 9 & 0.05 \\
\hline
\end{tabular}

* Significant at 0.05 level of probability

demonstrated significantly different numbers of whole word repetitions than part word repetitions (Table VI).

TABLE VI

Comparison of Target Discontinuities Within

54 to 60 Month 01d Age Group

Discontinuity Comparison

t d. $f$.

$\mathrm{p}$

$\begin{array}{lccc}\text { Part Word Repetition--False Start } & -0.54 & 9 & 0.05 \\ \text { Whole Word--Part Word Repetition } & -3.06 & 9 & 0.05 * \\ \text { Whole Word Repetition--False Start } & 1.79 & 9 & 0.05\end{array}$

* Significant at 0.05 level of probability

DISCUSSION

This investigation has sought to answer four questions relative to part word repetitions, whole word repetitions and false starts 
demonstrated by normal female preschool children. This investigation also sought to gain additional data to support or reject Starkweather's (1985) theory that certain discontinuities are more characteristic of immature speech, and thus may be classified as imature discontinuities. For purposes of this discussion the term discontinuity is a term that is currently used by Starkweather, who states that this term is more complete and appropriate when referring to normal children. In earlier studies the term disfluency was used, however, it is synonymous with the term discontinuity that is being used in this investigation.

\section{Part Word Repetitions}

Although the data did not completely support Starkweather's (1985) hypothesis, that 30 to 36 month old children demonstrate more part word repetitions, whole word repetitions and false starts than the 54 to 60 month old group, it did show a significant difference between part word repetitions between the two age groups, showing that 30 to 36 month old children did demonstrate more part word repetitions than the 54 to 60 month old group. This finding supports Starkweather's hypothesis that part word repetitions are "very immature." This is also the finding that this investigator had the most confidence in using to support Starkweather's theory of the direct relationship between age and the type of discontinuity demonstrated because Starkweather stated that part word repetitions are very immature. This investigation's data did not. however, support the remainder of Starkweather's hypothesis that whole word repetitions are quite immature and false starts are somewhat immature. In order to support this hypothesis in whole, the data would have needed to have shown that the 30 to 36 month old age group 
demonstrated more whole word repetitions and false starts than the 54 to 60 month old group. Had these results been found it would have provided stronger evidence in favor of a direct relationship between age and the type of discontinuity demonstrated.

Data from other studies investigating normal discontinuities in preschool children's speech have not supported Starkweather's (1985) hypothesis but similar to this study, have found certain findings that do support Starkweather's theory.

Similarities to Past Investigation on Part Word Repetitions. In comparing the present data of part word repetitions found in the younger age group to the data of past investigations of normal discontinuity in this age child, only one study had similar results (Table VII). Yairi and Lewis (1984) found that 2 and 3 year old males and females demonstrated significantly more part word repetitions than any other category demonstrating a mean of 1.39 part word repetitions per 100 syllables. This was the only study whose data was similar to that found by this investigator and whose results support Starkweather's (1985) hypothesis. All of the early 1930 and 1940 Iowa studies (Davis, 1939; Branscom, et a1, 1955; Johnson, 1955) found less part word repetitions for their preschoolers of all ages when comparing part word, whole word and phrase repetitions. When studying the data of these investigations and not the overall results of these studies more similarities between the investigations of the past and present can be found. Johnson combined the results of 2, 3 , and 4 year olds and found that this group demonstrated 1.22 part word repetitions per 100 words, this data is very similar to 1.50 part word repetitions per 100 words that was exhibited in this investigation. 
TABLE VII

PART WORD REPETITIONS' DATA IN PAST INVESTIGATIONS ON NORMAL CHILDREN'S SPEECH

This investigation's findings were:

30 to 36 month old normal female children - 1.50 part word repetitions

54 to 60 month old normal female children - 0.63 part word repetitions

SIMILAR DATA FINDINGS

DISSIMILAR DATA FINDINGS

30 to 36 Month o1d Children

1. Yairi and Lewis (1984) 1.39 1. DeJoy and Gregory (1985) 0.96

2. Johnson (1945) $1.22 \quad 2$. Wex1er (1982) stress 0.96

neutral 0.73

3. Wexler and Mysak (1982) 0.79

4. Yairi (1981) 0.96

54 to 60 Month 01d Children

1. Hughes (1943) $0.56 \quad 1$. DeJoy and Gregory (1985) 0.48

2. Yairi and Clifton 2. Wexler (1982) neutra1 0.39

(1972) $\quad 0.60$

3. Wex1er and Mysak (1982)

3. Wexler and Mysak (1982)

(6 years) 0.60

$(4$ years) 0.40

4. Wexler (1982)

( 4 years) stress 0.65

(6 years) stress 0.54

(6 years) neutra1 0.57

These data similarities can also be seen when comparing the results of past investigations and the data results of the 54 to 60 month old group in this investigation (Table VII). Hughes' (Branscom, et a1, 1955) 4 year o1d group demonstrated 0.56 part word repetitions 
per 100 words, Yairi and Clifton's (1972) 5 year old group demonstrated 0.60 part word repetitions per 100 words and Wexler and Mysak's (1982) 6 year olds demonstrated 0.60 part word repetitions per 100 words. This data is similar to this investigation's findings of 0.60 part word repetitions per 100 words for the 54 to 60 month old group.

\section{Dissimilarities to Past Investigations on Part Word Repetitions.}

DeJoy and Gregory's (1985), Wexler's (1982). Wexler and Mysak's (1982) and Yairi's (1981) data for the younger preschool children in their investigations were all markedly different than the findings of this investigation; all of these investigations showed less part word repetitions than this studies' findings. DeJoy and Gregory's 3 year 6 month olds demonstrated 0.79 part word repetitions per 100 words, Wex1er and Mysak's 2 year olds demonstrated 0.7 part word repetitions per 100 words, Wexler's 2 year olds demonstrated 0.96 part word repetitions in neutral speaking situations, and Yairi's 2 year olds demonstrated 0.96 part word repetitions per 100 words. DeJoy and Gregory's, Wexler's and Wexler and Mysak's data on older children found that this group demonstrated less part word repetitions than the results of this investigation indicated. DeJoy and Gregory's 5 year olds demonstrated 0.48 part word repetitions per 100 words in neutral stress speaking situations and Wexler and Mysak's 4 year olds demonstrated 0.40 part word repetitions per 100 words.

\section{Whole Word Repetitions}

Similarities to Past Investigations on Whole Word Repetitions. In comparing the data of whole word repetitions demonstrated by the 30 to 36 month old children to young preschool children of other 
investigations, similarities and differences can be seen (Table VIII). The 30 to 36 month old group of this investigation demonstrated 1.30 whole word repetitions per 100 words. This data is similar to Davis' (1939) finding of 1.66 whole word repetitions per 100 words for the 3 year old group. Oxtoby's (Branscom, et al, 1955) 3 year old group also showed similar results with 1.48 whole word repetitions per 100 words. Yairi's (1981) and Wexler's (1982) 2 year old groups also demonstrated similar means for whole word repetitions per 100 words with 1.12 and 1.36 .

Similarities can also be found when comparing whole word repetitions of 54 to 60 month old children to past investigations (Table VIII). Davis' (1939) 4 year old group demonstrated 1.24 whole word repetitions per 100 words and Yairi and Clifton's (1972) preschool children demonstrated 1.24 whole word repetitions per 100 words. Al1 three of these studies' findings are similar to this investigations findings of 1.37 whole word repetitions per 100 words. Dissimilarities to Past Investigation on Whole Word Repetitions. Differences can also be noted in comparing the results of this investigation to past studies. Branscom's, Hughes' (Branscom, et a1, 1955), Johnson's (1945), Wexler's (1982) and Wexler and Mysak's (1982) data a11 showed significantly more whole word repetitions per 100 words than this investigation. In most cases these investigators (Branscom, Hughes, Johnson, Wexler, and Wexler and Mysak) found double the number of whole word repetitions per 100 words than this investigation. Branscom's 3 year old group demonstrated 2.62 whole word repetitions per 100 words; Hughes' 2 year old group demonstrated 1.81 whole word repetitions per 100 words; Johnson's 2, 3, and 4 year old group demonstrated 2.78 
TABLE VIII

WHOLE WORD REPETITIONS' DATA IN PAST INVESTIGATIONS

ON NORMAL CHILDREN'S SPEECH

This investigation's findings were:

30 to 36 month old female children

54 to 60 month old female children

SIMILAR DATA FINDINGS
1.30 whole word repetitions

1.37 whole word repetitions

DISSIMILAR DATA FINDINGS

30 to 36 Month 01d Children

$\begin{array}{lllll}\text { 1. Davis (1939) (2 years) } & 1.66 & \text { 1. Branscom (1942) } & 2.62 \\ & & \text { 2. Hughes (1943) } & 1.81 \\ \text { 2. Oxtoby (1943) } & 1.48 & \text { 3. Johnson (1945) } & 2.78 \\ \text { 3. Yairi (1981) } & 1.12 & \text { 4. Wexler and Mysak (1982) } & 2.70 \\ \text { 4. Wexler (1982) stress } & 1.36 & \text { 5. Wexler (1982) neutra1 } & 2.11\end{array}$

54 to 60 Month 01d Children
1. Davis (1939)
1.24
1. Branscom (1942) (4 years) 2.48
2. Hughes (1943)
1.13
3. Yairi and Clifton (1972)
1.24
(5 years) 1.97
2. Haynes and Hood (1977)
(4 years) 2.16
(6 years) 0.96

3. Wexler and Mysak (1982)

( 4 years) 0.90

(6 years) 0.90

4. DeJoy and Gregory (1985) 0.78

5. Wexler (1982)

$$
\begin{array}{rr}
\text { (4 years) stress } & 0.78 \\
\text { neutra1 } & 0.89 \\
\text { (6 years) stress } & 0.94 \\
\text { neutra1 } & 0.86
\end{array}
$$


whole word repetitions per 100 words; Wexler's 2 year olds demonstrated 2.11 whole word repetitions per 100 words in neutral stress speaking situations and Wexler and Msak's 2 year olds demonstrated 2.7 whole word repetitions per 100 words. However, Yairi and Lewis' (1984) study of 2 and 3 year olds found 1.05 whole word repetitions per 100 syllables, which is markedly less than the findings of this investigation, but note that Yairi and Lewis' data was reported per 100 syllables and not per 100 words as most investigations.

Differences can also be noted when comparing the 54 to 60 month old group's results to past investigations. Branscom's (Branscom, et al, 1955) 4 year old group and 6 year old group demonstrated 2.48 and 1.97 whole word repetitions per 100 words and Haynes and Hood's (1977) 4 year old group exhibited 2.16 whole word repetitions per 100 words, all showing markedly more whole word repetitions than this investigation's findings. While Haynes and Hood's 6 year old group exhibited 0.96 whole word repetitions per 100 words, Wexler and Mysak's (1982) 4 and 6 year old groups exhibited 0.9 and 0.9 whole word repetitions per 100 words, DeJoy and Gregory's (1985) 5 year old group exhibited 0.78 whole word repetitions per 100 words and Wexler's (1982) 4 year olds in neutral stress speaking situations, demonstrated 0.89 whole word repetitions and 0.78 in stressful speaking situations, and the 6 year olds in neutral stress speaking situations demonstrated 0.86 and 0.94 in stressful speaking situations.

The results of this investigation concerning whole word repetitions does not support Starkweather's (1985) hypothesis that whole word repetitions are quite immature due to the fact that the 54 to 60 month old age group demonstrated more whole word repetitions than the 30 to 36 
month old age group. This difference was not statistically significant but due to the fact that the 30 to 36 month old group did not demonstrate more whole word repetitions than the older group, the hypothesis was not supported. In order to support the hypothesis, the 30 to 36 month old group would have needed to demonstrate more whole word repetitions than the 54 to 60 month old group. Although the data did not support Starkweather's hypothesis, this investigation's findings are similar to many other investigator's findings on whole word repetitions in normal children's speech (Table VIII).

\section{False Starts}

In comparing the data of false starts in this investigation to past investigations it is necessary to note that false starts are also referred to as revision-incomplete phrases. Some studies have reported revisions and incomplete phrases separately (DeJoy and Gregory, 1985; and Haynes and Hood, 1977) while other studies have reported them combined (Yairi and Lewis, 1984; Yairi and C1ifton, 1972; Wexler and Mysak, 1982: and Wexler, 1982). For purposes of clarification, the term false start rather than the term revision-incomplete phrase, will be used in this discussion to categorize this type of discontinuity.

After examining the data of all three types of discontinuities and comparing them to past investigations, the data on false starts is primarily dissimilar to past studies (Table IX). The 30 to 36 month old group and the 54 to 60 month old group both demonstrated 0.73 false starts per 100 words.

Similarities to Past Investigations on False Starts. The early Iowa studies of the 1930 s and 1940 s focused on $1 y$ on repetitions and did not 
TABLE IX

FALSE STARTS' DATA IN PAST INVESTIGATIONS

ON NORMAL CHILDREN'S SPEECH

This investigation's findings were:

30 to 36 month old female children

0.73 false starts

54 to 60 month o1d female children

0.73 false starts

SIMILAR DATA FINDINGS

DISSIMILAR DATA EINDINGS

30 To 36 Month old Children

$\begin{array}{lllll}\text { 1. Yairi (1981) } & 0.87 & \text { 1. Yairi and Lewis (1984) } 1.07\end{array}$

2. Wexler (1982) neutral 3.48

stress 2.62

3. Wexler and Mysak (1982) 3.50

54 to 60 Month 01d Children

1. Yairi and C1ifton (1972) 2.49

2. DeJoy and Gregory (1985)

(3.5 years) 3.61

$(5$ years) 3.00

3. Haynes and Hood (1977) 3.71

4. Wexler and Mysak (1982) 2.60

address false starts. Yairi's (1981) longitudinal study is the only past investigation with data similar to this investigation's. Yairi's 2 year olds demonstrated 0.87 false starts per 100 words. None of the past investigations involving 4 and 5 year olds showed results similar to those found in this investigation.

Dissimilarities to Past Investigations on False Starts. A11 other investigations dealing with false starts in the 2 year old age range 
showed markedly more false starts per 100 words than this investigation's data. Yairi and Lewis' (1984) 2 and 3 year olds demonstrated 1.07 false starts per 100 syllables, while Wexler and Mysak's (1982) 2 year olds demonstrated 3.5 false starts per 100 words and Wexler's (1982) 2 year olds demonstrated 3.48 false starts per 100 words in a neutral speaking situation and 2.62 false starts in stressful speaking situations.

In addition, data from past investigations dealing with normal children in the 4 and 5 year old age range also demonstrated markedly more false starts than the findings of this investigation. Yairi and C1ifton's (1972) preschool group (mean age of 5.6 years old) demonstrated 2.49 false starts per 100 words, while DeJoy and Gregory's (1985) 5 year olds demonstrated 3.0 false starts per 100 words. Wex1er and Mysak's (1982) 4 year olds demonstrated 2.6 false starts per 100 words, Wexler's (1982) 4 year olds demonstrated 2.6 and 2.56 in neutral stress speaking situations and stressful speaking situations and his 6 year olds demonstrated 2.25 and 2.24 in neutral stress speaking situations and stressful speaking situations, while Haynes and Hood's (1977) 4 year olds also demonstrated markedly more false starts with 3.49 false starts per 100 words than this investigation's findings of 0.73 false starts per 100 words.

The fact that the 30 to 36 month old children in this investigation did not demonstrate more false starts than the 54 to 60 month old group. does not support Starkweather's (1985) hypothesis that false starts are somewhat immature. As mentioned previously, in comparing part word repetitions, whole word repetitions and false starts, false starts are the type of discontinuity that an individual would have the 
least confidence in predicting immaturity, based upon Starkweather's hypothesis.

Comparison of This Investigation's Findings to Starkweather's (1985) Hypothesis

Starkweather's (1985) hypothesis that part word repetitions are very immature and whole word repetitions are quite immature and false starts are somewhat immature was developed primarily by analyzing the data from the Kowal. $0^{\prime}$ Connell and Sabin (1985) investigation. Kowal, $O^{\prime}$ Conne11 and Sabin examined the speech discontinuity of 168 children, twelve boys and twelve girls at seven age levels, from kindergarten through seniors in high school. Kowal, O'Connell and Sabin's investigation found that the highest occurring discontinuities at the kindergarten level were false starts occurring 29 times per 1,000 syllables and repetitions occurring 23 times per 1,000 syllables. Repetitions included part word, whole word and phrase repetitions. By fourth grade false starts had decreased from 29 to 26 per 1,000 syllables and repetitions had decreased from 23 to 14 repetitions per 1,000 syllables. Kowal. O'Connel1 and Sabin also reported that 24 percent of the total number of repetitions for all ages were part word repetitions, and were distributed among the younger children from kindergarten to fourth grade.

In comparing Kowal, O'Connell and Sabin's (1985) findings to this investigation similarities can be seen. Both studies supported Starkweather's (1985) hypothesis that part word repetitions are very immature and whole word repetitions are quite immature. Had Kowal. O'Connell and Sabin sampled younger children their results might have been similar to 
this investigation's findings if their data had been projected backwards. However, the results concerning false starts from this investigation did not show trends similar to Kowal, O'Connell and Sabin's investigation. This investigation found that both the 30 to 36 and the 54 to 60 month old children demonstrated markedly less false starts than the school population of Kowal. O'Connell and Sabin's investigation. It would be expected if Starkweather's hypothesis could be generalized to preschool children then the younger children should have demonstrated more false starts.

Starkweather (1985) also states that preschool continuity is simply too variable to develop standardized norms for normal discontinuity as Kowal. O'Connell and Sabin (1985) did for school age children. However, this investigator believes that after looking at the data from this investigation it is possible to speculate about preschool continuity, especially if a larger number of subjects are utilized and followed in a longitudinal study. Examining the results of this investigation and other investigations it can be seen that there are similar findings among studies in regard to percent of specific discontinuities demonstrated by preschool children, albeit, with a larger standard of deviations.

\section{VARIOUS FACTORS WHICH MAY AFFECT RESULTS}

\section{Procedures}

Many differences and similarities have been noted when comparing the results of this investigation to past studies investigating normal discontinuities. There are a number of factors that may explain why there are discrepancies between this investigation and past 
investigations. One factor is the manner in which the speech samples were collected for analyzing discontinuities. A variety of different procedures have been used between studies, for example, many different procedures have been used to elicit speech samples from children. Yairi and Clifton (1972) elicited spontaneous speech samples by having the children respond to picture cards and telling a once-upon-a-time story, while Wexler and Mysak (1982) gathered their speech samples while the children played with specific toys and materials. Early normal discontinuity studies also used a variety of procedures to gather speech samples; Davis (1939) and Oxtoby (Branscom, et al, 1955) observed the child during a free play situation while Branscom and Hughes (Branscom, et a1. 1955) administered a speech test that they had designed. Johnson (1955) used a combination of both procedures to obtain speech samples. Due to the fact that not enough research has been done to determine whether varying the speaking task affects normal discontinuity, it may be possible to conclude that this is a factor in the discrepancies among findings in different investigations. Wexler (1982) investigated 2, 4. and 6 year old's discontinuity in neutral and stressful speaking situations and found that there was a significant interaction between age and speaking condition for word repetitions, indicating that the differences between stressful speaking situations and neutral speaking situations varied as a function of age. Wexler also noted that there was large variability among the subjects and the relatively small number of subjects may explain the lack of significance noted in this investigation. This data supports the fact that differences in speaking tasks may affect discontinuity. 


\section{Transcription}

Another factor that may explain why there are similarities and differences among this investigation and earlier investigations is the manner in which the sample was transcribed. Early Iowa studies (Davis, 1939: Branscom, Hughes, and Oxtoby, 1955; and Johnson, 1955) transcribed the child's speech at the time the samples were gathered, although some investigators did use a coding system, there is sufficient evidence to show that recording behaviors by hand results in the greatest $10 s \mathrm{~s}$ of information and hinders the observation (B10om and Lahey, 1978). B100m and Lahey also emphasize that when using hand transcription there is very 1ittle time difference between the occurrence of the event and the observation of the event, the record of the event is therefore constrained by preconceptions and other limitations of observation. Lee (1974) also states that some utterances will be too long or too complicated to transcribe directly from memory, especially when dealing with discontinuties. Lee further states that an investigator's own auditory recall of an entire utterance cannot be depended upon. Therefore the findings of the early Iowa study can be questioned when examining the manner in which the samples were transcribed.

\section{Setting}

The setting in which the speech samples were gathered may also affect discontinuities, when comparing the results of this investigation to earlier investigations. In examining the $1930 \mathrm{~s}$ and $1940 \mathrm{~s}$ studies, speech samples were obtained by some investigators by having the child interact with an investigator in an unfamiliar clinic room (Branscom and Hughes [Branscom, et al, 1955], and Johnson, 1955) while other 
investigators observed the child in a free play situation in their preschool classroom with other children present. Later investigations of the $1970 \mathrm{~s}$ and $1980 \mathrm{~s}$ also varied the environment they chose to obtain the child's speech sample in. Yairi (1981) interacted with 2 year olds in his study at their homes or day care centers, while Wexler and Mysak (1982) obtained their speech sample in an unfamiliar playroom setting. There is again not enough information available to determine whether varying the environment the child is speaking in affects normal discontinuity, if there is such a relationship it may explain some of the discrepancies in data noted between investigations.

\section{Client Interaction}

The familiarity of the person interacting with the child is another factor that must be considered when comparing discrepancies among findings, to determine whether varying the person the child interascts with affects the child's discontinuity. Davis (1939) and Oxtoby (Branscom, et a1, 1955) gathered the speech sample while the children interacted with other children in a preschool setting while other studies had the children interacting with an investigator or another adult. Martin, Haroldson, and Kuhl (1972a and 1972b) conducted two studies of children interacting with different individuals. In one study children between the ages of 3 years, 6 months and 5 years old were observed interacting with their mother in one situation and a child in another situation. The second study observed 3 year, 6 month and 5 year old children interacting with a puppet in one situation and an unfamiliar investigator in the second situation. The results of both studies were similar. Martin, Haroldson, and Kuh1 discovered that 
approximately the same number of words were produced by each child in each of the four different situations and that the occurrence of discontinuities displayed by the children did not vary when interacting with four different individuals. A study by Silverman (1985), however, found somewhat different results when studying ten normal 4 year olds. The study observed the children interacting with other children and adults in their normal preschool setting and observed the children interacting with an investigator that was unfamiliar to them, in a experimental room at the preschool. The results indicated that the children demonstrated more discontinuities when interacting with the examiner. The results of both studies indicate a need for further research in this area to determine whether varying the person the child interacts with affects discontinuity and can explain variations found among investigations that were conducted differently.

\section{SUMMARY}

When considering the results of this investigation, it is necessary to note that this study has attempted to add additional information to our current literature on normal discontinuities in preschool children, however, it plays an even greater role acting as a segment of a longitudinal study on normal discontinuities in preschool children's speech being conducted by Portland State University's Speech and Hearing Department. To date there has been only one published 1ongitudinal study and it was 1imited to one year by Yairi (1981). It is imperative that more longitudinal studies be implemented in order to follow a large number of children over time, with consistent procedures. The current research being done at Portland State University has been 
very thorough in developing specific procedures, including a standard set of procedures for obtaining the sample and transcribing and analyzing the speech sample. These standard procedures will enable the investigation to be consistently carried out throughout the following years.

DeJoy and Gregory (1985), Starkweather (1985), and Yairi (1981) all state a need for a large sample study to be done on preschool children in order to discover developmental trends. Yairi researched thirty-three 2 year olds but formed the conclusion that even with thirty-three subjects there was a great deal of individual diversity in discontinuity and that the group mean loses much of its practical meaning. DeJoy and Gregory found that by inspecting the results of other preschool discontinuity investigations that their data revealed that the standard deviations were nearly equal to or slightly greater than the reported mean. These trends signal the need for relatively larger samples of children to be studied. The data from this current investigation showed a similar trend. In each of the three categories, for each age group. the standard deviations were equal to or slightly greater than the means. It should be investigated further whether significantly larger samples of children in each age group would decrease the influence of individual variablility and therefore more developmental trends would be evident. That is the purpose of the Iongitudinal study being undertaken at Portland State University. 
CHAPTER V

SUMMARY AND IMPLICATIONS

SUMMARY

The pupose of this study was to compare the frequency of occurrence of specific discontinuities in 30 to 36 month old normal female children to normal 54 to 60 month old female children. Specifically, the discontinuities were categorized as follows: part word repetitions, whole word repetitions, and false starts. The discontinuities were observed while the child spontaneously interacted with an investigator in a clincal room.

The following questions were addressed:

1) Do 30 to 36 month old normal female children differ in their total frequency of specific discontinuities when compared to normal 54 to 60 month o1d female children?

2) Do 30 to 36 month old normal female children demonstrate more part word repetitions than normal 54 to 60 month old female children?

3) Do 30 to 36 month old normal female children demonstrate more whole word repetitions than 54 to 60 month old normal female children?

4) Do 30 to 36 month old normal female children demonstrate more false starts than normal 54 to 60 month old female children?

Twenty normal female subjects from the greater Portland area were randomly selected from all children fitting selection criteria, to serve as subjects for this investigation. The group was divided into ten 
children from the 30 to 36 month old age group $(\bar{x}-33.7)$ and ten children from the 54 to 60 month old age group $(\bar{x}=57.7)$. Spontaneous speech samples were obtained for each subject. The subject's speech samples were transcribed verbatim from the recordings by the investigator, who then identified and classified specific discontinuities. A one way analysis of variance for independent means was performed to evaluate the degree of difference between all types of discontinuities in the two age groups. The results indicated a statistically significant difference exists between the two groups at the 0.05 level of probability for part word repetitions. Normal female children from the 30 to 36 month old age group demonstrated a significantly higher number of part word repetitions than the 54 to 60 month old age group. No other statistically significant differences were found.

In examining the data resulting from the study, it was concluded:

1) Normal female children from the 30 to 36 month old age group used significantly more part word repetitions than the 54 to 60 month old age group.

2) There was no statistically significant difference in the total targeted discontinuities between the two age groups of normal female children.

3) There was no statistically significant difference in the number of whole word repetitions used by the two age groups of normal female children.

4) There was no statistically significant difference in the number of false starts used by the two age groups of normal female children. The results of this study point to part word repetitions as a good indicator of speech immaturity in young preschool children. 
IMPLICATIONS

\section{Clinical}

One of the most important clincal implications for the speechlanguage pathologist arising from this study is that it provides additional information on normal discontinuities in preschool children's speech. There is a need for speech-language pathologists to have normative data in order to be able to differentially diagnose early childhood stuttering from normally disfluent speech behavior, since a goal of speech-1anguage pathologists is to identify young children who exhibit an abnormal amount of disfluent speech. Early diagnosis is critical in order to begin clinical intervention or to monitor the children over time. Additionally, more information on normal discontinuities in preschooler's speech can also aid the clinician in counseling parents of normally disfluent children who are concerned about their children's speech, by providing them with data that shows that this type of discontinuity is characteristic of all young children's speech to some degree, depending upon the number and type of discontinuity demonstrated.

\section{$\underline{\text { Research }}$}

The sma11 number of subjects used in this study limits the extent to which inferences can be made based on these results. In this study, 30 to 36 month old normal female children demonstrated significantly more part word repetitions than the 54 to 60 month old age group. Further research with larger numbers of subjects is needed to examine and substantiate these findings. It is also possible that with a larger number of subjects that statistical differences could be noted in the 
two other targeted discontinuity categories (i.e., whole word repetitions and false starts).

A possible future research idea is to investigate the same children used in this study one year later to determine what type of changes had occurred in the type of discontinuity they were demonstrating. This type of investigation may lead to more evident developmental trends in regard to normal discontinuity. The published longitudinal research on normal discontinuities in preschool children has been very limited, to date only one published longitudinal study in this area has been done (Yairi, 1981) and that was limited to the second year of life. Current researchers in the area of normal discontinuity agree that more longitudinal research is needed in order to further investigate developmental trends.

Additionally, it is suggested by this investigator, for future research purposes, that all discontinuities be examined when analyzing children's speech discontinuity. Identifying only three targeted discontinuities did not provide adequate information on the child's entire disfluent behavior and made the analysis more difficult when comparing the data from this investigation to past investigations. The only past investigations that isolated specific discontinuities for purposes of analysis was the early 1930 and 1940 studies done in Iowa under Johnson (1955). who focused solely on repetitions.

Additional information on normally disfluent children could also be gained by investigating more thoroughly the influence of varying the person interacting with the child while collecting the speech sample. for example primary caregiver versus investigator. This investigator's clinical impression is that video taping the child interacting with a 
primary caregiver would provide a much richer language sample and more opportunities for discontinuities to occur in the child's speech than what was displayed when interacting with the investigator, especially with 3 year olds. Another variation of this study could be accomplished by varying the environment the speech sample was gathered in and the stimuli that was presented to the child in order to elicit the speech sample. There is currently very little published research in this area to determine whether varying these factors affects the child's discontinuity.

Finally, an interesting variation of this investigation could be accomplished by comparing the type of discontinuity demonstrated by preschool children with similar Mean Length of Utterances (MU). Children would be grouped based upon their MLU and not their chronological age.

The results of these studies may have an important impact on direct clinical intervention by establishing thorough normative data on discontinuities in normal preschool children's speech. Future research may lead to discovering what factors affect normal children's discontinuity in speech, for example, varying the stressfulness of the speaking situation, the person interacting with the child, or the environment in which the speaking takes place. 


\section{B IBL IOGRAPHY}

BRANSCOM, M.E., HUGHES, J.. AND OXTOBY, E.T. (1955). Studies on nonfluency in speech of preschool children. In Johnson, W. (Ed.). Stuttering in children and adults. Minnesota: University of Minnesota.

BLOOM, L. AND LAHEY, M. (1978). Language Development and Language Disorder, John Wiley and Sons, New York.

DAVIS, D.M. (1939). The relation of repetitions in the speech of young children to certain measures of language maturity and situational factors. Part I. Journal of Speech Disorders, 4, 303-318.

DEJOY, D.A. AND GREGORY, H.H. (1985). The relationship between age and frequency of disfluency in preschool children. Journal of Fluency Disorders, 107-122.

DUNN, L.M. (1981). Peabody Picture Vocabulary Test - Revised. Circle Pines, Minnesota: American Guidance Service.

HAYNES, W.O. AND HOOD, S.B. (1977). Language and disfluency variables in normal speaking children from discrete chronological age groups. Journal of Fluency Disorders. 2, 57-74.

JOHNSON, W. (1955). Stuttering in Children and Adults. University of Minnesota Press, Minneapolis.

JOHNSON, W. (1961). Measurements of oral reading and speaking rate and disfluency of adult male and female stutterers and nonstutterers. Journal of Speech and Hearing Research, 14, 113-124.

KOWAL, S., O'CONNELL, D.C. AND SABIN, E.J. (1975). Development of temporal patterning and vocal hesitations in spontaneous narratives. Journal of Psycholinguistic Research, 3, 195-207.

LEE, L. L. (1974). Developmental Sentence Analysis, Northwestern University Press, Evanston, Illinois.

MARTIN, R.R., HAROLDSON, S.K., AND KUHL, P. (1972a). An experimenta1 treatment with two preschool stuttering children. Journal of Speech and Hearing Research, 4, 743-752.

MARTIN, R.R., HAROLDSON, S.K., AND KUHL, P. (1972b). Disfluencies in child-child and child-mother speaking situations. Journal of Speech and Hearing Research, 4, 753-762. 
PINDZOLA, R.H. AND WHITE, D.T. (1986). A protocol for differentiating the incipient stutterer. Language Speech and Hearing Services in Schools, 1, 2-11.

SANDER, E. (1961). Reliability of the Iowa speech disfluency test. Journal of Speech and Hearing Disorders, Monograph Supplement, 7. 21-30.

SILVERMAN, F.H. (1985). Research Design and Evaluation in SpeechLanguage Pathology and Audiology. Prentice-Hall Inc.. Englewood Cliffs, New Jersey.

STARKWEATHER, C.W. (1985). The development of fluency in normal children. In Stuttering Therapy: Prevention and Intervention with Children. Memphis, Tennessee: Speech Foundation of America.

VAN RIPER, C. (1972). Speech Correction: Principles and Methods, Prentice-Hall Inc., Englewood Cliffs, New Jersey.

WEXLER, D. (1982). Developmental disfluency in 2, 4, 6 year old boys in neutral and stress situations. Journal of Speech and Hearing Research, 25, 229-234.

WEXLER, K.B. AND MYSAK, E.D. (1982). Disfluency characteristics of 2-, 4-. and 6-year old males. Journal of Fluency Disorders, 7. $37-46$.

YAIRI, E. (1981). Disfluencies of normally speaking two-year old children. Journal of Speech and Hearing Research, 24,490-495.

YAIRI, E. AND CLIFTON, N. (1972). Disfluent speech behavior of preschool children, high school seniors and geriatric persons. Journal of Speech and Hearing Research, 4, 714-719.

YAIRI, E. AND LEWIS, B. (1984). Disfluencies at the onset of stuttering. Journal of Speech and Hearing Research, 27, 154-159. 
APPENDIX A

LETTER TO PARENTS AND PERMISSION TO PARTICIPATE IN STUDY FORM

Dear

I am a graduate student at Portland State University, under the supervision of Dr. Robert Casteel. I am conducting a study regarding normal disfluencies in preschool children's speech. I am trying to find out what type of repetitions normal children do when talking.

This study can be accomplished by a 15-minute video-taped interview with your child talking with me. These video-taped sessions will be held at Portland State University at a time that is good for both you and the department. Your child's name will not be used in reporting the results and the video-tapes will only be available to authorized University personnel. Your child may be excused from participation in this study at any time without penalty.

Before the video-taped session, your child will receive a brief test of word meaning called the Peabody Picture Vocabulary Test Revised. I will also tape a short conversation with your child at your child's nursery school or day care center. In addition to the taped interview, your child will receive a hearing screening test if she is between the ages of 54 to 60 months. You will also be asked to complete a brief questionnaire about your child's speech and language development, medical history, your family and any stuttering you have observed in family members.

Please complete the attached form, indicate your approval and willingness to participate in this study, and return the form to me as soon as possible in the envelope provided. It is important that I schedule the taping session as soon as possible. Please call me if you have any questions (654-5183). Thank you for your cooperation.

If you have any problems as a result of your participation in this study. please contact Victor C. Dah1, Office of Graduate Studies and Research, 105 Neuberger Hal1, Portland State University, 229-3423.

Sincerely,

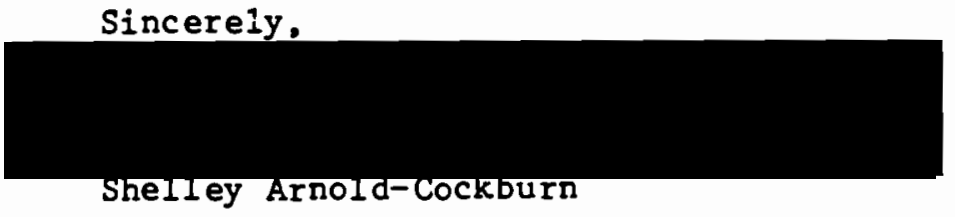


CHILD'S NAME NICKNAME

BIRTHDATE AGE

1. What is the primary language spoken in your home? Other?

2. Has your child had an ear infection within the last six months? Yes No

3. Has your child ever been diagnosed as demonstrating any of the following:

developmental delay? Yes No mental retardation? Yes No neurological impairment? Yes No orthopedic or physical handicap? Yes No

4. Has your child ever received speech therapy for stuttering? Yes No

I hereby give my permission for my child, to participate in this study. My child may attend a video-taping session and participate in the above-mentioned evaluation at an agreed upon date and time. I will complete the questionnaire, and I understand that I may withdraw my permission at any time during this study without penalty. 


\section{APPENDIX B}

QUESTIONNAIRE

Child's Name:

Birth Date:

\section{Address :} Telephone (day):

Relationship of person completing the quesitonnaire

What language is spoken mostly in your home?

Does your child speak another language? Yes

If so, what language?

What is your child's ethnic background?

I. List the children and adults living in your home.

NAMES

$\underline{A G E}$

RELATIONSHIP TO CHILD

II. Does your child stutter? Yes __ No __ (If no, go to Section III) When did you first notice that your child stutters?

Has anyone else comented on this? Yes _ No __ If so, who?

Have you consulted other professionals about your child's stuttering? Yes _ No __ If so, what were their recommendations?

What things have you tried, if any, to change your child's speech?

Does your child's speech change when she talks with:

(Answer Yes or No)

A friend

A younger sibling

An older sibling

A parent A familiar adult other than parent

A teacher (Or authority figure) In a small group

Describe other times when you notice changes in your child's speech 
When is your child's speech the best?

When is your child's speech the worst?

When your child stutters, what do you do?

When your child stutters, what does she do?

Describe what your child does when she stutters?

Does it bother your child? Yes No

Does it bother anyone else? Yes No

Does your child ever do any of the following when stuttering?

a. stretch sounds out? (Ex. mommy bal1)

Yes No

b. "get stuck" in the middle of words?

(Ex. b aseba11)

c. repeat words? (Ex. I-I-I want the ba11)

Yes

No

Yes No

d. repeat sounds? (Ex. I want the b-ba11)

e. repeat phrases? (Ex. I want I want the ba11)

Yes No

f. change a sentence? (Ex. I seen, I saw a cat)

Yes No

Does your child repeat: a $10 t$

a 1ittle

Yes No

Does your child repeat easily or with effort?

Easily

With Effort

III. Does your child do any of the following when speaking? (Yes or No)

Make faces Move the head Move arms/legs

Noisy breathing Lip smacking Tongue clicking other (describe)

When did your child say her first word?

What was your child's first word?

When did your child first walk?

When was your child toilet trained? 
Describe how your child learned to talk compared to other children in your family.

Early Late slow Basy Hard

Has your child ever attended school? Yes No

If so, where?

How long has your child attended school?

IV. Does any other member of your family stutter now or have they ever stutterd? Yes No
If so, who?
Name
Relationship to Child

\section{(OPTIONAL)}

What was the last grade completed in school by the primary caretaker of this child?

Occupation of caretaker? 
APPENDIX C

\section{LIST OF STIMULI}

\section{TOYS:}

1 telephone

2 cars

2 medium-sized rubber toys

1 wind-up toy

2 puppets

2 dol1s

Fischer Price Play. House

Tea and Plate Set

\section{QUESTIONS:}

Who lives at your house?

Te11 me about them.

What is your bedroom like?

Do you have any pets?

Tell me about them.

What do you do to take care of a pet?

What do you do at school?

Tell me about your friends.

What did you do for your last birthday?

Tell me about your favorite TV show.

Tell me how to brush your teeth.

Tell me how to make a peanut butter and jelly sandwich.

\section{PROMPTS:}

Tel1 me more.

What else?

Why?

MMM HMMM

Tell me about it.

Oh Wow. 
APPENDIX D

\section{INSTSTRUCTIONS FOR SELECTION OF CONTENT TRANSCRIPTS FOR RELIABILITY TESTING}

Video-tapes have been made of a child and an adult interacting in a parallel play situation. The children's conversations in these videotapes have been transcribed verbatim, and these transcripts are what you will be working from. You are responsible for extracting ten episodes from each of the six transcripts you are given and forming content transcript for each one. A content transcript can be defined as the basic information of an utterance provided by the child, deleting any type of discontinuity, such as; false starts, interjections, part word repetitions, whole word repetitions, phrase repetitions and prolongations, without the addition of any additional words that the child did not specifically speak. There are specific guidelines that you need to follow when developing these content transcripts.

A. Guidelines

1. Use episodes ten through nineteen from each of the six transcripts to form content episodes.

2. Additional words should not be added to the episodes, only use those words that are present in the transcripts.

3. It may be necessry with some episodes to include the full episode that was presented on the transcript, this is especially true if the episodes are very short and do not include any discontinuities. For example the following episodes would be 
included in the content transcripts in full:
a. hi
b. and those
c. her name is Sally

4. Discontinuities in the basic transcript should not be included in the content transcript, this includes: phrase repetitions, part word repetitions, whole word repetitions, prolongations, interjections and false starts. For example, "I-I-I am going" would be written, "I am going," and "uh I need uh I need to talk" would be written, "I need to talk."

5. In transcribing false starts into content episodes only include the most complete form of the episode. For example, "It is a ze-it is a giraffe" would be written, "It is a giraffe" and "Please set the chair-table" would be written. "Please set the table."

6. An unintelligible episode would be labeled as an unintelligible episode. If only part of the episode is unintelligible and the rest has been transcribed, label the unintelligible segment and include the transcribed section in its most completed form.

7. Any additional sounds or pulses at the beginning, middle or end of the episode should not be included in the content transcript.

B. Bxamples of Full Transcription and Corresponding Content Transcription

\section{Ful1 Transcription}

1. I don't know

2. I he I already tell him

\section{Content Transcription}

1. I don't know

2. I already tell him 
3. unintelligible episode

4. yah

5. you have a tea party with us?

6. w-w-wh-where is she?

7. I think sh-she got to sit

8. and when she wakes

(rest of utterance

unintel1igible)
3. unintelligible episode

4. yah

5. you have a tea party

with us?

6. where is she?

7. I think she got to sit

8. and when she wakes

(rest of utterance unintelligible) 
APPENDIX E

INSTRUCTIONS TO RELIABILITY JUDGES

PART ONE: Instructions for Selection of Content Transcripts for Reliability Testing

Read the attached instructions to the individual responsible for preparation of content transcription for reliability testing.

\section{PART TWO: General Instructions}

You will be given six partially complete transcripts, three from the 30 to 36 month old age group and three from the 54 to 60 month old age group. These transcripts contain ten episodes, and are only partially complete. The transcripts do not include any type of discontinuity, such as; interjections, part word repetitions, whole word repetitions, phrase repetitions, false starts. The transcripts contain only the content of the episodes. It is very important to remember that these transcripts may not be perfect, mistakes can be made even in determining the content of the episodes. It is very important not to accept the episode as correct just because you are cueing into key words, listen to the entire episode and see if you agree with all the words that have been given to you, then add the additional words you are hearing along with all discontinuities.

The purpose of this reliability testing is to determine the investigators accuracy at identifying whole word repetitions, part word repetitions, and false starts. The following are definitions of these terms: 
1. False Starts: The term false start refers to instances in which the content of a phrase is modified in which there is a grammatical modification or semantic modification. Changes in the pronounciation of a word are also counted as false starts. This term is used synonomously with revision-incomplete phrases. Examples: That's a ze that's a giraffe I was-I am going

2. Part Word Repetitions: The term part word repetition refers to repetitions of parts of words, either syllable or sound. No matter how many syllables or sounds may be repeated per word, only one discontinuity is credited.

Example: $d-d-d o g$

$$
\text { ta-ta-able }
$$

3. Whole Word Repetitions: The term whole word repetition refers to repetitions of whole words, including words of one or more syllables. The following are examples of whole word repetitions: "I-I-I going" or "going-going." No matter how many times a word is repeated it is only credited as one discontinuity.

PART THREE: Procedures for Transcription and Identification of Discontinuities

An individual not involved with the study has prepared six, randomly selected, content transcripts. Reliability raters will be given these transcripts. A technician will then play the corresponding segment of the video-tape that matches the content transcripts, the technician will initially show the reliability raters all ten episodes at once while the raters observe the episodes in their entirety. The 
technician will then play the video-tape segment again only showing the raters one episode at a time. The raters will be responsible for filling in all missing parts of the transcripts, including words that have been deleted and all discontinuities. The rater will then identify the target discontinuities. It should also be noted that the raters are responsible for making any changes in the transcripts due to errors made by the individual selecting content transcripts.

The raters may at any time ask the video technician to replay the episode. It is necessary that this be the only talking during reliability testing, raters should not discuss episodes with one another.

The following rules should be used when transcribing and identifying discontinuities:

1. Raters are only responsible for identification of whole word repetitions, part word repetitions, and false starts.

2. Identify part word repetitions by marking pw above the part word repetitions, and whole word repetitions by marking ww over the whole word repetition.

3. No matter how many times a whole word or part word is repeated it is only credited as one discontinuity.

4. An episode may have a combination of any of the three discontinuity types, and should be credited as separate discontinuities if this occurs.

Examples: Ky-Kyle Kyle 1 part word repetition and 1 whole word repetition

Th-The-The table-the tablet 1 part word repetition, 1 whole word repetition and 1 false start 
5. Repetitions of the first part of a contraction such as; "it-it's" and "I'-I'm" should be credited as a part word repetition since the contraction functions as a single word for the young child and was calculated as one word when determining the 300 word count for the initial transcripts.

6. Identify false starts by marking fs above the false start in the episode.

7. Whole words that are repeated, but are separated by interjections are not credited as whole word repetitions.

Examples: They uh uh They

8. Interjection repetitions are not credited as either part word repetitions or whole word repetitions.

PART FOUR: Reliability Training

A training session will be conducted prior to the actual reliability testing, by the investigator, using the same procedures as outlined above. The training session will include practice identification of three different content transcripts. The reliability raters must be 100 percent in agreement with each other in order to start reliability testing, any differences will be discussed with all members of the reliability team until everyone is in agreement over the discontinuity identification. 